$1 / 1 / 21-9385(1)$

SANDIA REPORT

- $\quad$ SAND93-8576 - UC-401

Unlimited Release

Printed June 1993

\title{
Unimolecular Decomposition of Methyltrichlorosilane: RRKM Calculations
}

Submitted to The Journal of Physical Chemistry

T.H. Osterheld, M.D. Allendorf, C.F. Melius

\footnotetext{
Prepared by

Sandia National Laboratories

Albuquerque, New Mexico 87185 and Livermore, California 94551

for the United States Department of Energy

under Contrued DE-AC04-76DP00789
} 
Issued by Sandia National Laboratories, operated for the United States Department of Energy by Sandia Corporation.

NOTICE: This report was prepared as an account of work sponsored by an agency of the United States Government. Neither the United States Government nor any agency thereof, nor any of their employees, nor any of the contractors, subcontractors, or their employees, makes any war. ranty, express or implied, or assumes any legal liability or responsibility for the accuracy, completeness, or usefulness of any information, apparafus, product, or process disclosed, or represents that its use would not intringe privately owned rights. Reference herein to any speciflc commerclal product, process, ir service by trade name, trademark, manufacturer, or otherwise, dors not necessarily constitute or imply its endorsement, recommendation, or favoring by the United States Government, any agency thereof or any of their contractors of subconractors. The views and ofinions expressed herein do no necessarily state or reflect thuse of the United States Government, any agency thereof or any of their contractors or subcontractors.

This report has been reproduced from the best available copy.

Available to DOE and DOE contractors from:

Office of Scientific and Technical Information

P.O. Box 62

Oak Ridge TN 37831

Prices available from (615) 576-8401, FTS 626-8401.

Available to the public from:

National Technical Information Service

U.S. Department of Commerce

5285 Port Royal Rd.

Springfield, VA 22161 
$\mathrm{UC}-401$

SAND93-8576

Unlimited Release

Printed June 1993

\title{
Unimolecular Decomposition of Methyltrichlorosilane: RRKM Calculations*
}

\author{
Thomas H. Osterheld, Mark D. Allendorf, and Carl F. Melius \\ Combustion Research Facility \\ Sandia National Laboratories/California \\ Livermore, CA 94551-0969
}

\begin{abstract}
Based on reaction thermochemistry and estimates of Arrhenius A-factors, it is expected that Si-C bond cleavage, $\mathrm{C}-\mathrm{H}$ bond cleavage, and $\mathrm{HCl}$ elimination will be the primary channels for the unimolecular decomposition of methyltrichlorosilane. Using RRKM theory, we calculated rate constants for these three reactions. The calculations support the conclusion that these three reactions are the major decomposition pathways. Rate constants for each reaction were calculated in the high-pressure limit (800-1500 K) and in the falloff regime (1300-1500 K) for bath gases of both helium and hydrogen. These calculations thus provide branching fractions as well as decomposition rates. We also calculated bimolecular rate constants for the overall decomposition in the low-pressure limit. Interesting and surprising kinetic behavior of this system and the individual reactions is discussed. The reactivity of this chlorinated organosilane is compared to that of other organosilanes.
\end{abstract}

*This work was supported by the U. S. Department of Energy, Office of Industrial Technologies, Advanced Industrial Concepts Materials Program. 


\section{Introduction}

The high-temperature reaction chemistry of chlorinated organosilanes is of intrinsic interest to the field of organosilicon chemistry. Although the thermochemistry ${ }^{1,2}$ and reactions of organosilanes have been studied extensively, particularly with regard to the importance of silylenes, ${ }^{3-5}$ comparable investigations of chlorinated organosilicon compounds have not been performed. Methylsilane $\left(\mathrm{CH}_{3} \mathrm{SiH}_{3}\right)$ pyrolysis, for example, has been investigated in some detail, ${ }^{6-9}$ but we are aware of only one study of the pyrolysis of chloromethylsilanes. ${ }^{10}$ The reactivity of chlorinated organosilicon compounds differs from simple organosilanes primarily because $\mathrm{Si}-\mathrm{Cl}$ bonds (in tetravalent compounds) are considerably stronger $\left(111-118 \mathrm{kcal} \mathrm{mol}^{-1}\right)^{11}$ than either $\mathrm{Si}-\mathrm{H}\left(90-95 \mathrm{kcal} \mathrm{mol}^{-1}\right)^{1}$ or $\mathrm{Si}-\mathrm{C}\left(90-94 \mathrm{kcal} \mathrm{mol}^{-1}\right)^{1}$ bonds. These strong bonds contribute to higher activation barriers for the elimination/insertion reactions that are so prevalent ${ }^{6-9}$ in organosilicon systems. This limits the (unimolecular) reactivity of the silicon functionality and allows access to reactions involving the alkyl group. For example, we will provide evidence that $\mathrm{C}-\mathrm{H}$ bond cleavage can contribute significantly to chlorinated organosilane pyrolysis. This reaction is not typically expected to play an important role in organosilicon pyrolysis, based on both kinetic and thermochemical arguments. . $^{2,12,13}$

In addition to their fundamental chemical importance, chlorinated organosilanes have widespread industrial applications. They serve, for example, as precursors to polydimethylsiloxanes, ${ }^{14}$ which find applications ranging from dielectric media to hydraulic fluids and lubricants. Chlorinated organosilanes are also commonly employed in chemical vapor deposition (CVD) processes used to produce silicon carbide ( $\mathrm{SiC}$ ) coatings, thin films, composites, and powders. Currently, a variety of new methods for depositing SiC are under consideration, operating at both atmospheric ${ }^{15,16}$ and sub-atmospheric pressure. ${ }^{17-19}$ One of the most common reactants used in these processes is methyltrichlorosilane $\left(\mathrm{CH}_{3} \mathrm{SiCl}_{3}\right.$; MTS), which is favored because it is non-pyrophoric and inexpensive. It has been shown that MTS decomposes under typical SiC CVD conditions (atmospheric pressure, deposition temperatures $>1400 \mathrm{~K}$ ), producing $\mathrm{HCl}, \mathrm{SiHCl}_{3}, \mathrm{SiCl}_{4}, \mathrm{CH}_{4}$, as well as other silanes and hydrocarbons. ${ }^{20,21}$ These decomposition products result from both primary and secondary reaction pathways. Models used to optimize and scale-up new SiC CVD processes require detailed knowledge of the gas-phase chemistry for two important reasons. First, the high activation energies of MTS unimolecular reactions may make them the rate-limiting step in the deposition, particularly for low-temperature processes. Second, the surface reactivity of the various gas-phase product species, as characterized by a reactive sticking coefficient $\Gamma$, varies widely. Saturated molecules such as $\mathrm{SiCl}_{4}$ react with ${ }^{22} \Gamma \leq 10^{-3}$, while radicals such as $\mathrm{SiH}_{\mathrm{n}}(\mathrm{n}=0-3)$ are known to react with much higher efficiency, ${ }^{23-26} \Gamma \sim 0.1-1.0$. Thus, in order to accurately predict deposition rates, the concentrations of the various species present in the gas phase must be known. Unfortunately, we are aware of only one report in the literature that discusses the kinetics of the gas-phase decomposition of MTS. ${ }^{21}$ That paper has been widely cited but contains no data by which the measurements can be critically evaluated.

Recently we reported estimates of thermodynamic properties of molecules in the Si-C-Cl-H system, obtained from $a b$ initio calculations using the BAC-MP4(SDTQ) method. ${ }^{11}$ The structure and energetics of a transition state for the 1,2-elimination of $\mathrm{HCl}$ from MTS were also included in that study. These data allow activation energies for several possible MTS decomposition pathways 


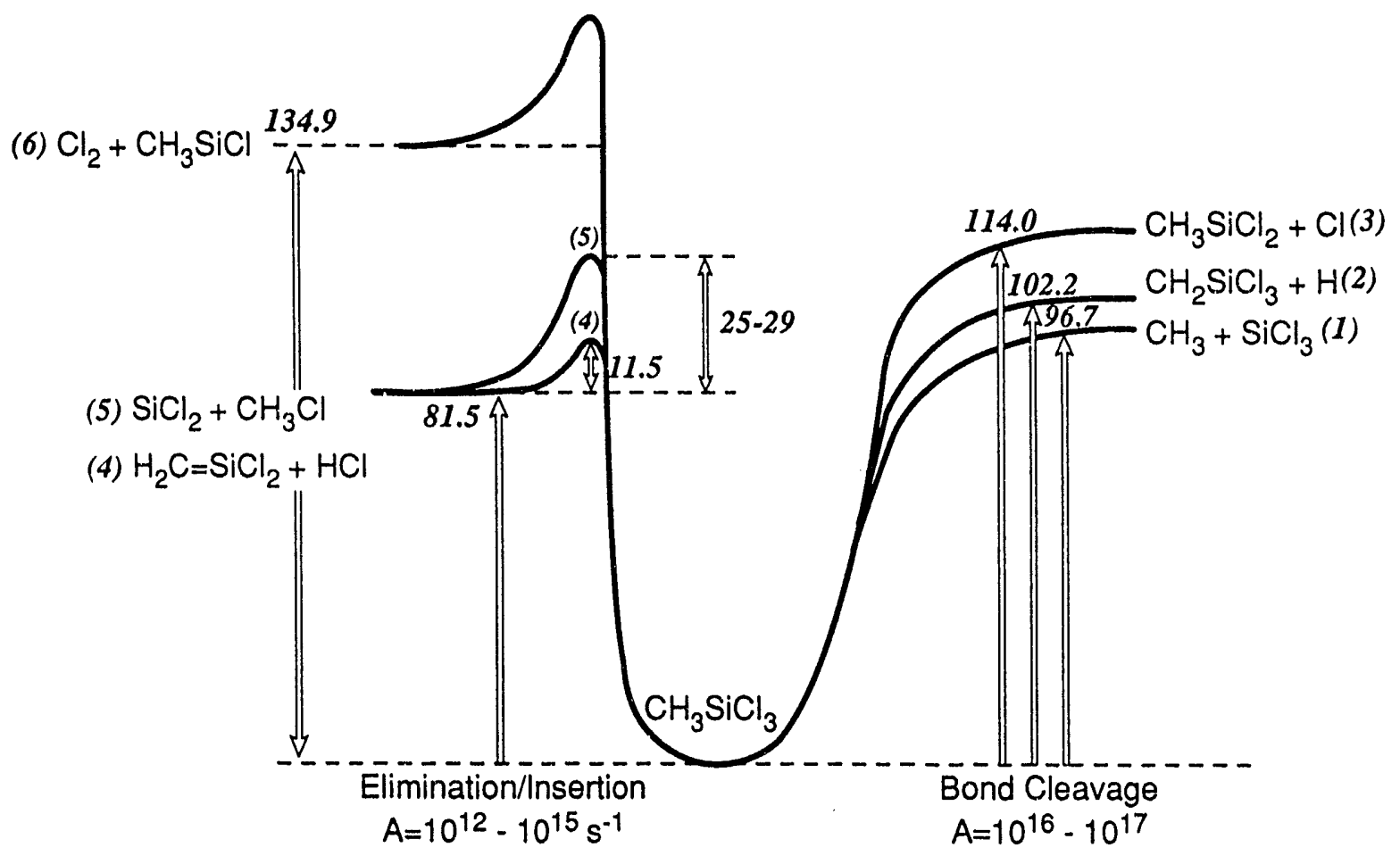

Figure 1: Potential energy diagram showing potential channels for unimolecular decomposition of MTS. Barrier heights and heats of reaction are relative to MTS and are based on thermodynamic data from Reference 11 . The values were calculated for $298 \mathrm{~K}$.

to be estimated (Figure 1). When combined with estimates of reaction A-factors, ${ }^{12}$ the results indicate that the three most important processes are the cleavage of the $\mathrm{Si}-\mathrm{C}$ bond to yield $\mathrm{CH}_{3}$ and $\mathrm{SiCl}_{3}$ (Reaction 1), loss of a methyl $\mathrm{H}$-atom (Reaction 2), and the 1,2-elimination of $\mathrm{HCl}$, forming the organosilane $\mathrm{Cl}_{2} \mathrm{Si}=\mathrm{CH}_{2}$ (Reaction 4):

$$
\begin{aligned}
& \mathrm{CH}_{3} \mathrm{SiCl}_{3} \rightarrow \mathrm{CH}_{3}+\mathrm{SiCl}_{3} \\
& \mathrm{CH}_{3} \mathrm{SiCl}_{3} \rightarrow \mathrm{CH}_{2} \mathrm{SiCl}_{3}+\mathrm{H} \\
& \mathrm{CH}_{3} \mathrm{SiCl}_{3} \rightarrow \mathrm{H}_{2} \mathrm{C}=\mathrm{SiCl}_{2}+\mathrm{HCl}
\end{aligned}
$$

In a previous paper, we reported calculations of the rate coefficient in the limit of high pressures for Reactions (1), (2), and (4); these results were used to estimate the high-pressure branching fraction for the decomposition. ${ }^{27}$ The calculations in this earlier work used a simplified version $^{28}$ of the statistical adiabatic channel (SAC) model developed by Quack and Troe ${ }^{29}$ to estimate $k$. Rates determined by this method are higher than those obtained from more sophisticated ${ }^{28}$ treatments, such as Rice-Ramsperger-Kassel-Marcus (RRKM) theory, ${ }^{30}$ and can thus be considered an upper bound for the MTS decomposition rate. We also estimated the pressure dependence of Reaction (1) using empirical expressions that describe the transition between the high- and low-pressure limiting rates as a function of pressure. ${ }^{31}$ Although this 
method is useful for processes in which only a single reaction channel is involved, it will not accurately predict the pressure dependence for systems that involve significant branching.

In this paper, we use statistical theory ${ }^{12,30-48}$ to calculate rate constants for the unimolecular decomposition of MTS in bath gases of helium or hydrogen. We report rate constants in the high- and low-pressure limits, as well as the complete pressure dependence, for the primary unimolecular decomposition pathways available to MTS (Reactions 1, 2, and 4). The results were obtained through the application of RRKM theory. For calculations in the falloff regime and low-pressure limit, we used bath gases of hydrogen or helium since typical CVD processes use a hydrogen bath gas and there is interest in using inert bath gases. We also report branching fractions as a function of temperature and pressure. The branching fractions allow us to evaluate the importance of organosilicon species to the SiC deposition process. The rate coefficients obtained are compared with the earlier experimental measurement ${ }^{21}$ by Burgess and Lewis (BL) of the decomposition of MTS in hydrogen. The calculated rate constant is considerably slower than the BL rate, which was mcasured at atmospheric pressure in a flow reactor. In a concluding section, we discuss the significance of these calculations to the field of organosilicon chemistry as well as their implications for SiC CVD processes.

\section{Theoretical Methods}

Thermal reaction rate coefficients were calculated using RRKM transition state theory. Specifically, RRKM theory is used to calculate the microcanonical reaction rate coefficients, $k(E, J)$, which are the rate coefficients for a particular energy $(\mathrm{E})$ and angular momentum state $(\mathrm{J})$ of a molecule. The $k(E, J)$ are then used to calculate thermal rate coefficients which correspond to those measured experimentally. In the high-pressure limit the thermal rate is obtained by averaging the $k(E, J)$ over Boltzmann equilibrium distributions of energy and angular momentum. ${ }^{30}$ At lower pressures (referred to as the falloff regime) the reactant energy and angular momentum distributions are no longer Boltzmann. In this regime, the $k(E, J)$ are incorporated into a master equation which also accounted for collisions and collisional energy transfer. ${ }^{30}$ Solution of the master equation provides the thernal rate coefficient. The calculations in this paper were accomplished using the UNIMOL suite of Gilbert, Jordan, and Smith ${ }^{49}$ after making minor modifications to the RRKM program. An excellent description of RRKM theory and the methods used in performing a calculation can be found in the recent book by Gilbert and Smith, ${ }^{30}$ as well as in many other books and articles. ${ }^{12,30-48}$

Our calculations involve modeling reactions having both loose and tight transition states. A loose transition state arises in a bond cleavage reaction where the two fragments are separated by large distances in the transition state. Reactions (1), (2), and (3) have loose transition states. Usually the motions of the fragments about axes perpendicular to the breaking bond are relatively unhindered (hence the term loose) and are thus treated as 2-dimensional rotors. These rotors contribute significantly to the entropy of the transition state, giving rise to the large Arrhenius A-factors typical of bond cleavage reactions. ${ }^{12}$ On the other hand, a tight transition state is encountered whenever a reaction requires significant atom rearrangement, as in isomerization or elimination/insertion reactions. Usually the transition state has some critical structure (hence the term tight) and even if two products are formed, the transition state does not have the two fragments separated by large distances. Reactions (4)-(6) have tight transition states. 
The location of the loose transition state along the reaction coordinate (i.e. on a Morse potential) was determined by canonical variational transition state theory, which means that the transition state was chosen to be the structure that gives the minimum rate in the high-pressure limit. ${ }^{30}$ This method requires knowledge of how molecular parameters such as vibrational frequencies and rotational constants change along the reaction coordinate. We used the Gorin model to account for this. ${ }^{12,30,32-34}$ The Gorin model assumes that the transition state is very product-like so that each of the two fragments has the structure and vibrational frequencies of the separated products. The separation between the two fragments that gives the minimum rate is then determined using the proper rotational constants for the external and internal rotors at each separation as well as the potential energy at that position on the reaction coordinate. ${ }^{12,30,32-34}$ The two dimensional rotors of the separating fragments were treated as either hindered rotors or sinusoidal hindered rotors. ${ }^{32}$ Steric hindrance was accounted for by the hard-sphere model of Benson in which the density of states for the two dimensional internal rotors are scaled by a factor that involves the angle through which the fragment can rotate before a steric interaction occurs. ${ }^{12,30,32-34}$ A steric interaction is assumed to occur when hard spheres having radii corresponding to the van der Waals radii of each atom touch. It should be noted that this treatment does not allow for the gradual transition from a free rotor to a sterically hindered rotor and can thus overestimate the steric hindrance. ${ }^{32}$ Rotational constants of external and internal rotors, for all of the transition states as well as the reactant, were obtained using the GEOM program from the UNIMOL suite. ${ }^{49}$

Structural features and thermodynamic data for the reactant, tight transition states, and for the individual fragments in the simple bond cleavage processes were taken from $a b$ initio electronic structure calculations using the BAC-MP4(SDTQ) method. ${ }^{1,11,50}$ When possible, vibrational frequencies were obtained from the literature and used in the calculations ( $\mathrm{MTS}, \mathrm{SiCl}_{3}$, and $\left.\mathrm{CH}_{3}\right) .30,51,52$ These frequencies were also compared to the vibrational frequencies from the $a b$ initio calculations to account for the systematic overestimation of the calculated frequencies. ${ }^{53}$ For this system, the $a b$ initio calculations appear to overestimate the vibrational frequencies by about $8 \%$. When no literature frequencies were available, as in the case of the $\mathrm{HCl}$ loss transition state and the $\mathrm{H}$ loss transition state, $a b$ initio frequencies were used after scaling by $8 \%$. Reaction thresholds were also determined by ab initio calculations. For the discussion in this paper the reaction threshold refers to the critical energy $\left(E_{\mathrm{o}}\right)$ of a reaction, which is the minimum energy required for an isolated molecule to undergo reaction (the enthalpy difference between the reactant and transition state at $0 \mathrm{~K}$ ).

The nature of collisions between reactant molecules and the bath gas contribute to the pressure dependence of the reaction rate. Unfortunately, little data is available on collisional energy transfer between chlorinated or alkylated silanes and $\mathrm{He}$ or $\mathrm{H}_{2}$. We therefore used the semi-empirical biased random walk (BRW) model to estimate parameters for collisional energy transfer into internal modes of the reactant. ${ }^{54-56}$

Parameters for the RRKM calculations are given in Tables I and II. The parameters include: vibrational frequencies, rotational constants for the external $\left(B_{\text {ext }}\right)$ and internal $\left(B_{\text {int }}\right)$ rotors, symmetry and degeneracy factors $(\sigma)$, critical energies, and in the case of the loose transition states the $D_{\mathrm{e}}$ and $\beta$ parameters for the Morse potential. The rotational constants in Table II are for the 1200 to $1500 \mathrm{~K}$ temperature range which are the temperatures used for the falloff 
Table I. RRKM Parameters for Methyltrichlorosilane and the $\mathrm{HCl}$ loss transition state

\section{$\mathrm{CH}_{3} \mathrm{SiCl}_{3} \quad \mathrm{CH}_{2} \mathrm{SiCl}_{2} \cdots \mathrm{HCl}{ }^{\dagger}$}

Vibrational Frequencies

$\begin{array}{lll}2991^{\mathbf{b}}(2)^{c} & 805(2) & 235(2) \\ 2917 & 762 & 228 \\ 1411(2) & 572(2) & 164(2) \\ 1270 & 452 & \end{array}$

$B_{\text {ext }}(\mathrm{act}), \sigma_{\mathrm{i}} \quad 0.04335,1$

$B_{\text {int }}, \sigma_{i}, \operatorname{dim} \quad 5.436,3,1$

$\sigma_{\text {sym }} / \mathrm{n}=3$
Vibrational Frequencies

3154

3071

1413

1193

1186

936
$830 \quad 232$

$732 \quad 202$

$630 \quad 196$

$487 \quad 53$

$465 \quad 48$

406
53

a Frequencies and rotational constants are in units of $\mathrm{cm}^{-1}$

b Frequencies from Reference 48

c Degeneracy of vibration

calculations. We have used the typical treatment for external rotors, in which the molecule or transition state is approximated as a symmetric top. The rotor around the unique axis is treited as active and able to exchange energy with vibrations while, the degenerate 2-dimensional rotor is treated as inactive or uncoupled from the vibrational modes. ${ }^{30}$

Choosing parameters for the reactant is fairly straightforward, although a question arises over how to deal with the torsional vibration. According to the $a b$ initio calculation, this vibration in MTS occurs at $165 \mathrm{~cm}^{-1}$ (the torsion is not observed in the infrared or Raman spectra because of its symmetry). This degree of freedom is treated as a free internal rotor even though the vibrational frequency is fairly high, ${ }^{30}$ because the reactions are modeled at high temperatures where we would expect that a free rotor is more appropriate.

For the loose transition states (Reactions (1) and (2)), we treated the two dimensional rotors as sinusoidal hindered rotors. ${ }^{32}$ We also calculated rates without the sinusoidal potential for the 2-dimensional rotors. These rates (in the high-pressure limit) are about $30 \%$ faster than those using sinusoidal hindered rotors but the exact values are not reported in this paper. As indicated earlier, steric hindrance was accounted for by the hard sphere model of Benson. ${ }^{12}$

At room temperature it is easy to locate the transition state for Reaction (1) using the techniques described above. As the temperature is raised, the transition state moves to smaller 
Table II. RRKM Parameters for Si-C and C-H bond scission transition states ${ }^{\mathbf{a}}$

\begin{tabular}{|c|c|c|c|c|c|}
\hline \multicolumn{3}{|c|}{$\mathrm{CH}_{3} \cdots \mathrm{SiCl}_{3}^{\dagger}$} & \multicolumn{3}{|c|}{$\mathrm{H} \ldots \mathrm{CH}_{2} \mathrm{SiCl}_{3}^{\dagger}$} \\
\hline \multicolumn{3}{|c|}{ Vibrational Frequencies } & \multicolumn{3}{|c|}{ Vibrational Frequencies } \\
\hline $3162^{\mathbf{b}}(2)^{\mathbf{c}}$ & 580 & 254 & 3180 & & 230 \\
\hline 3044 & $582^{d}(2)$ & $176(2)$ & 3086 & & 227 \\
\hline \multirow[t]{3}{*}{$1396(2)$} & 470 & & 1429 & & 165 \\
\hline & & & 796 & & 157 \\
\hline & & & 787 & & \\
\hline \multicolumn{2}{|c|}{$\mathrm{B}_{\text {ext }}($ inact $), \sigma_{\mathrm{i}}$} & $0.03329,1$ & \multicolumn{2}{|c|}{$\mathrm{B}_{\text {ext }}(\mathrm{inact}), \sigma_{\mathrm{i}}$} & $0.04742,1$ \\
\hline \multicolumn{2}{|l|}{$\mathrm{B}_{\mathrm{ext}}(\mathrm{act}), \sigma_{\mathrm{i}}$} & $0.04277,1$ & \multicolumn{2}{|c|}{$\mathrm{B}_{\mathrm{ext}}(\mathrm{act}), \sigma_{\mathrm{i}}$} & $0.05914,1$ \\
\hline \multicolumn{2}{|c|}{$B_{\text {int }}, \sigma_{i}, \operatorname{dim}$} & $4.884,3,1$ & \multicolumn{2}{|c|}{$\mathrm{B}_{\mathrm{int}}, \sigma_{\mathrm{i}}, \operatorname{dim}$} & $7.268,3,1$ \\
\hline \multicolumn{2}{|c|}{$\mathrm{B}_{\mathrm{int}}, \sigma_{\mathrm{i}}, \operatorname{dim}$} & $0.06897 \mathbf{e}, 1,2$ & \multicolumn{2}{|c|}{$B_{\text {int }}, \sigma_{i}, \operatorname{dim}$} & $0.01775,1,2$ \\
\hline \multicolumn{2}{|c|}{$\mathrm{B}_{\mathrm{int}}, \sigma_{\mathrm{i}}, \operatorname{dim}$} & $9.681,2,2$ & & & \\
\hline \multicolumn{2}{|l|}{$\mathrm{D}_{\mathrm{e}}$} & $99.9 \mathrm{kcal} / \mathrm{mol}$ & \multicolumn{2}{|l|}{$\mathrm{D}_{\mathrm{e}}$} & $108.9 \mathrm{kcal} / \mathrm{mol}$ \\
\hline \multicolumn{2}{|l|}{$\mathrm{D}_{\mathrm{o}}$} & $95.4 \mathrm{kcal} / \mathrm{mol}$ & \multicolumn{2}{|l|}{$D_{0}$} & $100.8 \mathrm{kcal} / \mathrm{mol}$ \\
\hline \multicolumn{2}{|l|}{$\beta$} & $1.82 \AA^{-1}$ & \multicolumn{2}{|l|}{$\beta$} & $1.86 \AA^{-1}$ \\
\hline \multicolumn{2}{|l|}{$\sigma_{\text {sym }} / n=3$} & $\sigma_{\mathrm{el}}=4$ & \multicolumn{2}{|c|}{$\sigma_{\mathrm{sym}} / \mathrm{n}=1$} & $\sigma_{\mathrm{el}}=4$ \\
\hline
\end{tabular}

a Frequencies and rotational constants are in units of $\mathrm{cm}^{-1}$

b Frequencies for $\mathrm{CH}_{3}$ from Reference 26

c Degeneracy of vibration

d Frequencies for $\mathrm{SiCl}_{3}$ from Reference 49

e Average hindrance $\Theta=48^{\circ}$

fragment separations. ${ }^{30}$ However, over the "high" temperature range used for our calculations, the transition state is not as easy to locate. A problem arises because the hard sphere model used to account for steric hindrance causes a discontinuity in the rates for Reaction (1) at fragment separations in which the methyl rotor becomes hindered. The discontinuity is an artifact in the calculation and has been described previously. ${ }^{30,32,33}$ The basic difficulty is that the hindering in the hard sphere model turns on abruptly and strongly so that for Reaction (1), it overestimates the steric hindrance for the methyl rotor. ${ }^{32}$ We dealt with this by not allowing the methyl rotor to become sterically hindered. This treatment is similar to that of Jordan, Smith, and Gilbert. ${ }^{32}$ It is possible that we should have included some steric interaction for this rotor but a priori we have no criteria for choosing the amount of steric interaction. It should be noted that we did include steric 
hindrance for the $\mathrm{SiCl}_{3}$ rotor in this transition state. We describe below why we believe our treatment is the most appropriate and then we show by calculations with extreme steric hindrance that our treatment appears correct.

The special treatment of the methyl rotor appears reasonable for several reasons. First, it allows for an unambiguous application of variational transition state theory. Second, error introduced by failing to hinder the rotor should be at least partially offset by including the symmetry of the rotor $(\sigma=2)$. Including the symmetry results in a lower sum of states than otherwise but would probably not be appropriate if the rotor were significantly hindered. Third, the use of a sinusoidal potential already provides a lower sum of states than the free rotor potential traditionally used in the past. Fourth, when we hindered the methyl rotor the transition state was located at a position that gave a meaningless rotational constant for the rotor. ${ }^{30}$ This indicates that strict use of the hard sphere model is inappropriate and results in a significant underestimate of the contribution of these modes to the sum of states in the transition state. ${ }^{30}$ Finally, test calculations in which we hindered this rotor to any significant degree actually gave rates slower than if the two dimensional rotor had been treated as two $300-400 \mathrm{~cm}^{-1}$ vibrations. Treating the modes as vibrations of this magnitude is an unrealistically tight treatment in our estimation. Since the high pressure rates calculated in the very hindered extreme of $300-400 \mathrm{~cm}^{-1}$ vibrations are only up to a factor of 3 slower than our treatment, we expect that any error introduced from the ambiguity in treating these modes should be minor.

The transition state for $\mathrm{HCl}$ elimination (Reaction (4)) has two low-frequency librations. These modes were treated as vibrations and not as a 2-dimensional rotor since an analysis of the hard sphere steric interactions indicated that a rotor would be completely hindered. This view is supported by a normal mode analysis of the $a b$ initio force field. ${ }^{57}$ The reason these two modes have such low frequencies is because they are librations involving a relatively heavy $\mathrm{HCl}$ group.

\section{Results}

Before discussing the RRKM results, it is useful to review the thermodynamics of the various MTS decomposition pathways, as determined from our previous ab initio calculations. 1,11,27 Figure 1 shows the potential energy curves and reaction enthalpies of several possible MTS decompositions. All of the possible products are considerably higher in energy than MTS (by an amount $\geq 81.5 \mathrm{kcal} / \mathrm{mol}$ ). In addition, Reactions (4) and (5), which are the lowestenergy reactions based on product thermodynamics, have potential energy barriers. This results in a minimum reaction threshold for any channel of at least $93.0 \mathrm{kcal} / \mathrm{mol}$. At energies above this, there are 5 possible reactions in an energy range of about $20 \mathrm{kcal} / \mathrm{mol}$. At much higher energies, Reaction (6), which involves breaking strong $\mathrm{Si}-\mathrm{Cl}$ bonds, also becomes thermodynamically accessible.

We have categorized these reactions as either bond cleavages, having loose transition states with typical Arrhenius A-factors ${ }^{12}$ of $10^{16}-10^{17} \mathrm{~s}^{-1}$, or elimination/insertion reactions, having tight transition states with typical A-factors ${ }^{12}$ of $10^{12}-10^{15} \mathrm{~s}^{-1}$. On the basis of these categories and the thermodynamics discussed above, it is a simple matter to remove reactions from consideration that are so slow that they are unlikely to contribute much to the overall decomposition. 
Reaction (6), elimination of $\mathrm{Cl}_{2}$, which has both a low A-factor because of a tight transition state and a threshold at least $35 \mathrm{kcal} / \mathrm{mol}$ higher than the lowest energy reaction can immediately be removed from consideration.

Reaction (3), loss of $\mathrm{Cl}$, which is the highest energy bond cleavage, can also be eliminated from consideration. We calculated high pressure A-factors using the methods of Benson ${ }^{12}$ and found that the A-factor for this reaction was essentially identical to that for Reaction (1) (Si-C bond scission). The much higher threshold $(113.4 \mathrm{kcal} / \mathrm{mol}$ compared to $95.4 \mathrm{kcal} / \mathrm{mol})$ indicates that it should not contribute significantly to the decomposition. This proposal is further strengthened by the observation that Reaction (2) has a significantly higher A-factor than Reaction (3) (vide infra) and as such would be expected to dominate the higher threshold reaction.

Finally, Reaction (5), elimination of $\mathrm{CH}_{3} \mathrm{Cl}$, can be removed from consideration. Although attempts to calculate this transition state using $a b$ initio theory were unsuccessful, we estimate that its threshold will be higher than that for Reaction (1) ( $\mathrm{Si}-\mathrm{C}$ bond scission). ${ }^{27}$ Since Reaction (5) has a much smaller A-factor than Reaction (1), it is not expected to be significant. This conclusion is borne out by the relatively minor contribution of Reaction (4) (the other low-energy elimination) to the overall decomposition (vide infra).

We have thus modeled the decomposition of MTS by calculating rates for $\mathrm{CH}_{3}$ loss, $\mathrm{H}$ loss, and $\mathrm{HCl}$ elimination (Reactions (1), (2), and (4)). It is expected that these three reactions are the major contributors to the thermal unimolecular decomposition.

A. High Pressure Limit. In the high pressure limit, collisions with the bath gas are sufficiently rapid that energy and angular momentum have equilibrium Boltzmann distributions. ${ }^{30}$ As a consequence, reaction rate coefficients do not depend on the total pressure and are even independent of each other in the case of multi-channel reactions. Therefore, the high pressure unimolecular rate coefficient, $k_{\text {uni }}^{\infty}$, is the canonical average of the $k(E, J)$ from RRKM theory and can be calculated without resorting to a master equation. ${ }^{30}$ For the bond cleavage reactions (Reactions (1) and (2)), $k_{\text {uni }}^{\infty}$ is the rate which is minimized when applying canonical variational transition state theory (the method used in this paper). The high pressure rate coefficients were calculated at temperatures ranging from $800 \mathrm{~K}$ to $1500 \mathrm{~K}$ for the three reactions of interest. Since these rate constants are for the high-pressure limit they are, of course, independent of bath gas. The calculated high-pressure rate coefficients and reaction parameters are given in Table III. As can be seen from these results, $\mathrm{H}$ loss is the most efficient reaction at the higher temperatures. At $1100 \mathrm{~K}$ it is about $40 \%$ faster than $\mathrm{CH}_{3}$ loss and as the temperature is increased, $\mathrm{H}$ loss becomes even more dominant. At $1500 \mathrm{~K}$ it has a rate coefficient that is at least a factor of 5 larger than the other reactions. It should also be noted that according to these calculations, Reaction (4) never contributes significantly to the decomposition; over the 800-1500 K temperature range it contributes less than $0.2 \%$ to the overall rate coefficient. These calculations are useful for comparing the efficiency of the various channels especially since they are relatively easy to perform. However, as will be secn below, the high-pressure limit is never achieved in CVD reactors. 
Table III. High Pressure Reaction Rates and Parameters for Methyltrichlorosilane

\begin{tabular}{|c|c|c|c|c|}
\hline $\mathrm{T}(\mathrm{K})$ & $\begin{array}{l}\text { Reaction } \\
\text { Product } \\
\end{array}$ & $k_{\text {uni }}^{\infty}\left(s^{-1}\right)$ & $\log \left(A^{\infty} / s^{-1}\right)$ & $\mathrm{E}_{\mathrm{a}}^{\infty}(\mathrm{kcal} / \mathrm{mol})$ \\
\hline \multirow[t]{4}{*}{800} & $\mathrm{HCl}$ & $9.6 \times 10^{-12}$ & 15.1 & 95.5 \\
\hline & $\mathrm{CH}_{3}$ & $5.4 \times 10^{-9}$ & 18.3 & 97.4 \\
\hline & $\mathbf{H}$ & $1.5 \times 10^{-9}$ & 19.5 & 103.6 \\
\hline & total & $6.9 \times 10^{-9}$ & & \\
\hline \multirow[t]{4}{*}{900} & $\mathrm{HCl}$ & $7.6 \times 10^{-9}$ & 15.1 & 95.7 \\
\hline & $\mathrm{CH}_{3}$ & $4.0 \times 10^{-6}$ & 18.3 & 97.5 \\
\hline & $\mathrm{H}$ & $2.1 \times 10^{-6}$ & 19.5 & 103.7 \\
\hline & total & $6.1 \times 10^{-6}$ & & \\
\hline \multirow[t]{4}{*}{1000} & $\mathrm{HCl}$ & $1.6 \times 10^{-6}$ & 15.2 & 96.0 \\
\hline & $\mathrm{CH}_{3}$ & 0.00078 & 18.2 & 97.5 \\
\hline & $\mathrm{H}$ & 0.00068 & 19.5 & 103.8 \\
\hline & total & 0.0015 & & \\
\hline \multirow[t]{4}{*}{1100} & $\mathrm{HCl}$ & 0.00013 & 15.2 & 96.3 \\
\hline & $\mathrm{CH}_{3}$ & 0.057 & 18.1 & 97.4 \\
\hline & $\mathrm{H}$ & 0.078 & 19.5 & 103.8 \\
\hline & total & 0.135 & & \\
\hline \multirow[t]{4}{*}{1200} & $\mathrm{HCl}$ & 0.0051 & 15.3 & 96.5 \\
\hline & $\mathrm{CH}_{3}$ & 2.0 & 18.0 & 97.5 \\
\hline & $\mathrm{H}$ & 4.1 & 19.5 & 103.8 \\
\hline & total & 6.1 & & \\
\hline \multirow[t]{4}{*}{1300} & $\mathrm{HCl}$ & 0.12 & 15.3 & 96.7 \\
\hline & $\mathrm{CH}_{3}$ & 40 & 18.0 & 97.5 \\
\hline & H & 120 & 19.5 & 103.8 \\
\hline & total & 160 & & \\
\hline \multirow[t]{4}{*}{1400} & $\mathrm{HCl}$ & 1.7 & 15.4 & 96.9 \\
\hline & $\mathrm{CH}_{3}$ & 510 & 17.9 & 97.5 \\
\hline & $\mathrm{H}$ & 2000 & 19.5 & 103.8 \\
\hline & total & 2500 & & \\
\hline
\end{tabular}


Table III. High Pressure Reaction Rates and Parameters for Methyltrichlorosilane (continued)

\begin{tabular}{ccccc}
\hline $\mathrm{T}(\mathrm{K})$ & $\begin{array}{c}\text { Reaction } \\
\text { Product }\end{array}$ & $\mathrm{k}_{\text {uni }}^{\infty}\left(\mathrm{s}^{-1}\right)$ & $\log \left(\mathrm{A}^{\infty} / \mathrm{s}^{-1}\right)$ & $\mathrm{E}_{\mathbf{a}}^{\infty}(\mathrm{kcal} / \mathrm{mol})$ \\
\hline 1500 & $\mathrm{HCl}$ & 17 & 15.4 & 97.1 \\
& $\mathrm{CH}_{3}$ & 4700 & 17.9 & 97.5 \\
& $\mathrm{H}$ & 24000 & 19.5 & 103.8 \\
& total & 29000 & &
\end{tabular}

B. Falloff Regime. As the pressure is decreased from the high-pressure limit, collisions between reactant and bath gas are no longer sufficiently rapid to maintain Boltzmann energy and angular momentum distributions. ${ }^{30}$ Thus, reaction drains away population from levels above the critical energy $\left(E_{0}\right)$. To obtain the energy distribution and reaction rate coefficient one must resort to a master equation which also accounts for collisions and collisional energy transfer. In this regime, the thermal reaction rate does depend on the total pressure. ${ }^{30}$ In a multi-channel system the rate of a specific pathway is also influenced by the other reactions. Ultimately, at very low pressures, the reaction reaches the low-pressure limit where conversion of the activated reactant to product is sufficiently faster than collisions that any molecule with $E>E_{0}$ reacts before it can be deactivated by collisions. ${ }^{30}$ At this point the reaction becomes first order in bath gas pressure. ${ }^{30}$ The falloff regime connects the high- and low-pressure limits and is the region where neither collisional energy transfer nor chemical reaction dominate, but both play a contributing role in the overall kinetics. The falloff regime spans several orders of magnitude of pressure and at high temperatures many unimolecular reactions, even at atmospheric pressure, are far from the high-pressure limit. MTS is a large, heavy molecule with many low frequency modes. This means that the high-pressure limit will only occur at extremely high pressures--much higher than atmospheric. ${ }^{30}$ Thus, from a practical point of view, rates in the falloff regime are very important, since most CVD processes operate in the 10-760 torr region.

Reaction rates in the falloff region were calculated at $1300 \mathrm{~K}, 1400 \mathrm{~K}$, and $1500 \mathrm{~K}$ for $\mathrm{He}$ and $\mathrm{H}_{2}$ bath gases. Figure 2 shows the dependence of the overall thermal decomposition rate on temperature and pressure over a $10^{-3}$ to $10^{6}$ torr pressure range. Based on the calculation discussed in the next section, helium is expected to transfer more energy per collision than hydrogen, which leads to the prediction of slightly higher rates for a helium bath gas at a given temperature and pressure. As can be seen in these plots, even at pressures as high as $10^{6}$ torr the rate constant does not reach its high-pressure limiting value.

C. Collisional Energy Transfer. In the falloff regime and at the low-pressure limit, the energy distribution of reactant molecules (and thus the reaction rate) depends on the energy transfer occurring in collisions between a reactant molecile and bath gas molecule. To include this effect in the determination of a thermal rate coefficient, one must choose a model for energy transfer and obtain the appropriate values for the energy transfer parameters. Usually the best strate gy is to find experimentally measured values of the energy transferred per collision, either for the system of interest or similar systems, and apply the apprc priate model. 

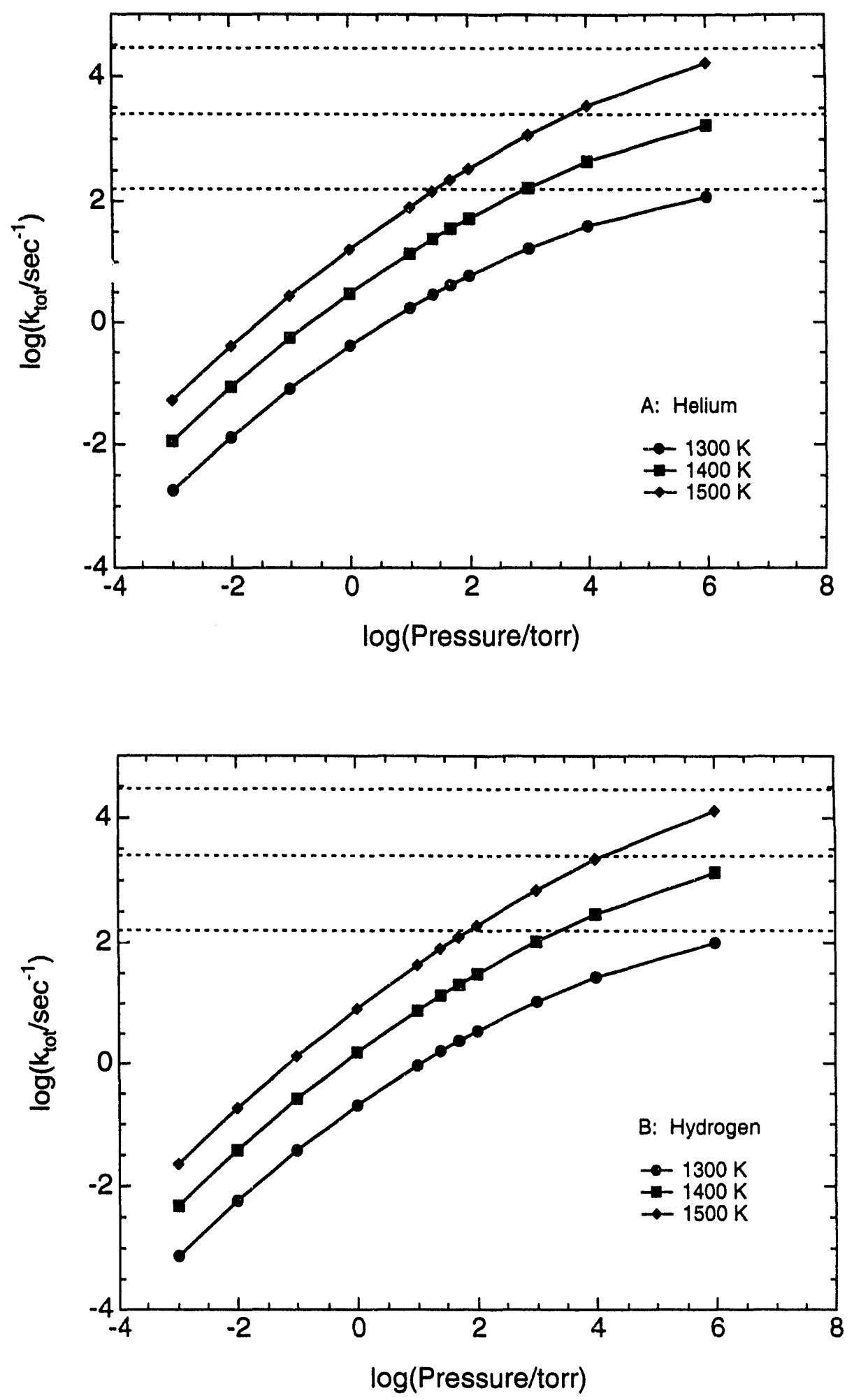

Figure 2: RRKM predictions for the total MTS decomposition rate as a function of temperature and pressure. Dashed lines indicate the high-pressure limit for each temperature.

(A) helium bath gas; (B) hydrogen bath gas. 
However, as mentioned earlier, little information is available on collisional energy transfer between chlorinated or alkylated silanes and the bath gases of interest. For this reason we used the semi-empirical BRW model for collisional energy transfer. ${ }^{54-56}$ This model assumes that, during a collision, energy exchange between the internal degrees of freedom of the excited molecule and the bath gas is essentially random but constrained by microscopic reversibility and total-energy conservation. In the BRW model the collisional energy transfer is characterized by the quantity $s=\left(t_{c} D_{E}\right)^{1 / 2}$ where $t_{c}$ is the duration of a collision and $D_{E}$ is an "energy diffusion coefficient". This model has been tested by comparison with trajectory calculations and incorporates many essential features of the collision dynamics including a temperature dependence. Values of the parameter $s$ calculated for this study are given in Table IV. Equivalent $\Delta E_{\text {down }}$ (the average downward energy transferred per collision ${ }^{30}$ in the exponential-down model) are also reported in Table IV. Since the corresponding $\Delta E_{\text {down }}$ values for helium are fairly large, ${ }^{58}$ we also calculated rate coefficients with the helium $s$ values divided by two. The $s / 2$ value should provide a lower bound for the collisional energy transfer. It should be noted, however, that the calculated values in Table IV are not unreasonable when compared to values obtained at intermediate temperatures for alkyl isocyanides. ${ }^{59}$ In the final analysis, calculations of the overall rates as well as branching fractions are fairly insensitive to the collisional energy transfer parameter. This is shown in Figure 3, where, at pressures higher than 10 torr in $\mathrm{He}$, the rates calculated using $s$ and $s / 2$ are within about a factor of 2 of each other.

D. Reaction Branching. Figures 4 and 5 show the results of falloff calculations for the rates of the individual reactions at $1300 \mathrm{~K}$ and $1500 \mathrm{~K}$ respectively. Comparison of the rates in these two plots shows that the reaction branching has only a minor dependence on the temperature or the collisional energy transfer (based on a comparison of helium and hydrogen bath gases). Although we have not included plots at $1400 \mathrm{~K}$ or using $s / 2$ for helium, they also support these conclusions. Rate constants for the individual reactions at selected pressures are given in Table V.

Table $\mathrm{V}$ and Figures 4 and 5 have several interesting features. First, loss of $\mathrm{HCl}$ has the lowest threshold by at least a $1.0 \mathrm{kcal} / \mathrm{mol}$ but, because of its relatively tight transition state compared to the bond scissions, it only contributes a small fraction to the overall reaction rate at these temperatures and pressures. Second, with increasing temperature, the rate at a given pressure is further from the high-pressure limit (Table V). At atmospheric pressure the total rate at $1300 \mathrm{~K}$ in a hydrogen bath gas is expected to be about $6 \%$ of the high-pressure rate while at 1500 $\mathrm{K}$ it is expected to be about $2 \%$ of the high pressure rate. The third and most interesting feature is the fast rate for Reaction (2) at pressures of ca. 10 torr or higher, even though this channel has a threshold at least $5 \mathrm{kcal} / \mathrm{mol}$ higher than Reaction (1).

The importance of Reaction (2) arises from its looser transition state relative to Reaction (1), which results in an A-factor an order of magnitude larger than $\mathrm{Si}-\mathrm{C}$ bond scission (Table III). This larger A-factor is surprising, since atom loss reactions involve transition states with only one 2-dimensional rotor instead of the two associated with polyatomic leaving groups. For bondcleavage reactions, the 2 -dimensional rotors usually contribute the most to the entropy increase between reactant and transition state. This results in bond-cleavage reactions having larger A-factors than tight transition states. ${ }^{12}$ Therefore, one would usually expect a transition state with only one 2-dimensional rotor to have a lower entropy compared with a transition state having two 
Table IV. Methyltrichlorosilane Collisional Energy Transfer Parameters from BRW Modela

\begin{tabular}{cccccccc}
\hline & \multicolumn{1}{c}{$\mathrm{He}^{\mathbf{b}}$} & \multicolumn{3}{c}{$\mathrm{H}_{2}$} \\
\cline { 2 - 7 } $\mathrm{T}(\mathrm{K})$ & $\mathrm{S}$ & $\Delta \mathrm{E}_{\text {down }}$ & $1 / 2 \mathrm{~S}$ & $\Delta \mathrm{E}_{\text {down }}$ & $\mathrm{S}$ & $\Delta \mathrm{E}_{\text {down }}$ \\
\hline 1300 & 614.5 & 795.6 & 307.25 & 369.8 & 346.2 & 420.9 \\
1400 & 663.1 & 853.2 & 331.55 & 398.2 & 385.2 & 468 \\
1500 & 714.4 & 913.8 & 357.2 & 427.8 & 422.6 & 512.5
\end{tabular}

a $s$ and $\Delta \mathrm{E}_{\text {down }}$ in units of $\mathrm{cm}^{-1}$

b Collision partner

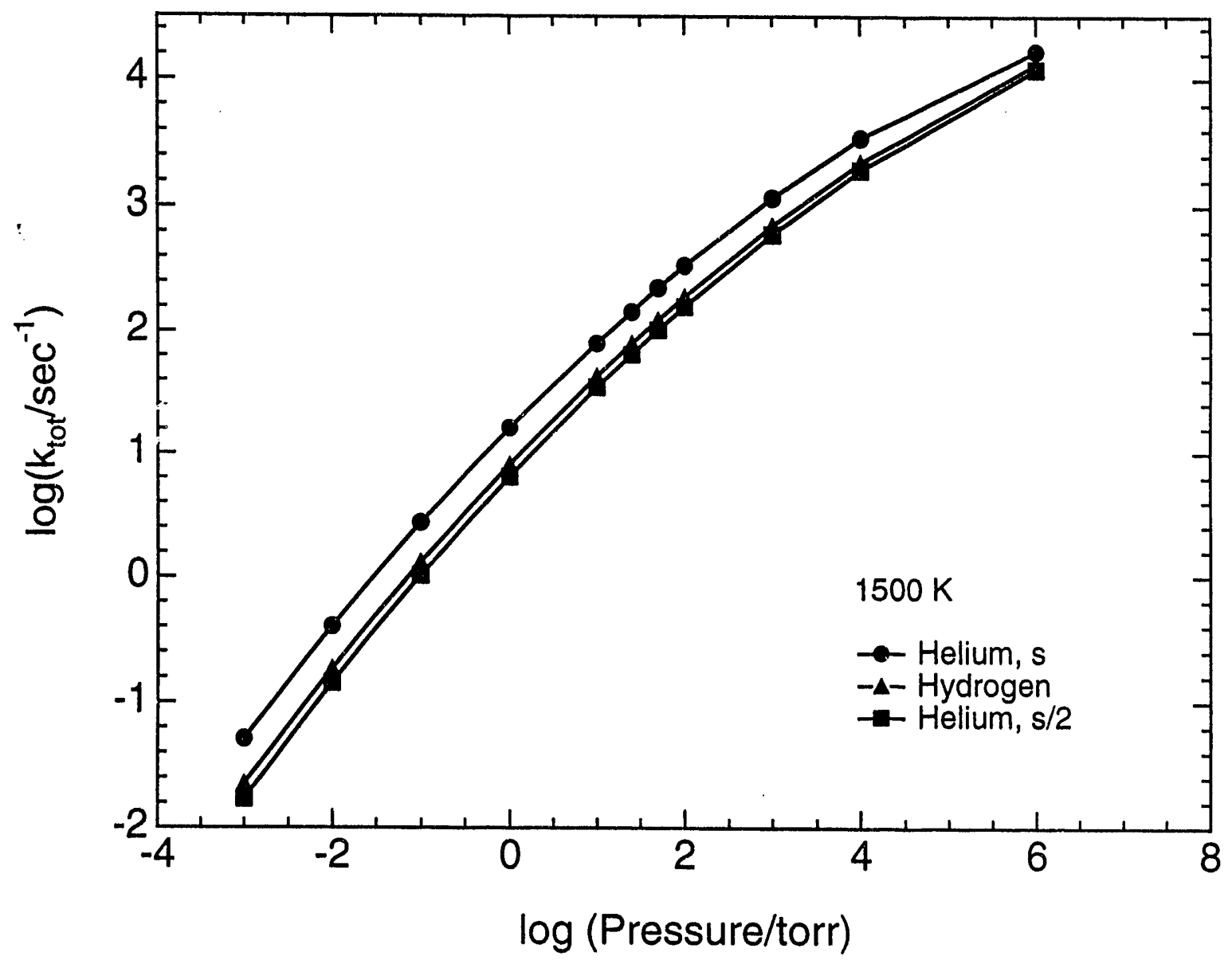

Figure 3: Comparison of RRKM predictions for the total MTS decomposition rate as a function of pressure for different bath gases and amount of energy transferred per collision (as characterized by the parameter $s$ in the BRW model; see text.) 
Table V. Rate Coefficients for Reactions of Methyltrichlorosilane

\begin{tabular}{|c|c|c|c|c|c|c|}
\hline Bath Gas & $\mathrm{T}(\mathrm{K})$ & $\mathrm{P}$ (torr) & $\mathrm{k}_{\mathrm{HCl}}\left(\mathrm{s}^{-1}\right)$ & $\mathrm{k}_{\mathrm{CH}_{3}}\left(\mathrm{~s}^{-1}\right)$ & $\mathrm{k}_{\mathrm{H}}\left(\mathrm{s}^{-1}\right)$ & $\mathrm{k}_{\mathrm{tot}} / \mathrm{k}_{\mathrm{uni}}^{\infty}$ \\
\hline \multirow[t]{20}{*}{$\mathrm{He}$} & 1300 & 10 & 0.00307 & 1.63 & 0.0967 & 0.0111 \\
\hline & & 25 & 0.0051 & 2.63 & 0.262 & 0.0186 \\
\hline & & 50 & 0.00729 & 3.66 & 0.522 & 0.0269 \\
\hline & & 100 & 0.0102 & 4.95 & 0.985 & 0.0381 \\
\hline & & 760 & 0.0231 & 10.3 & 4.73 & 0.0964 \\
\hline & & 1000 & 0.0254 & 11.2 & 5.67 & 0.108 \\
\hline & & \multicolumn{4}{|c|}{ In low-pressure limit, $\mathrm{k}_{\mathrm{o}}=4.63 \times 10^{8} \mathrm{~cm}^{3} \mathrm{~mol}^{-1} \mathrm{~s}^{-1}$} & \\
\hline & 1400 & 10 & 0.025 & 13.1 & 0.834 & 0.00547 \\
\hline & & 25 & 0.0432 & 21.9 & 2.33 & 0.00953 \\
\hline & & 50 & 0.0636 & 31.3 & 4.78 & 0.0142 \\
\hline & & 100 & 0.0914 & 43.6 & 9.29 & 0.0208 \\
\hline & & 760 & 0.228 & 98.6 & 49.0 & 0.0581 \\
\hline & & 1000 & 0.254 & 108 & 59.6 & 0.0661 \\
\hline & & \multicolumn{4}{|c|}{ In low-pressure limit, $\mathrm{k}_{\mathrm{O}}=2.72 \times 10^{9} \mathrm{~cm}^{3} \mathrm{~mol}^{-1} \mathrm{~s}^{-1}$} & \\
\hline & 1500 & 10 & 0.145 & 75.0 & 5.12 & 0.00276 \\
\hline & & 25 & 0.261 & 130 & 14.7 & 0.00498 \\
\hline & & 50 & 0.394 & 191 & 30.8 & 0.00763 \\
\hline & & 100 & 0.583 & 273 & 61.5 & 0.0115 \\
\hline & & 760 & 1.58 & 667 & 353 & 0.0351 \\
\hline & & 1000 & 1.78 & 740 & 435 & 0.0404 \\
\hline
\end{tabular}

In low-pressure limit, $\mathrm{k}_{\mathrm{o}}=1.17 \times 10^{10} \mathrm{~cm}^{3} \mathrm{~mol}^{-1} \mathrm{~s}^{-1}$

$\begin{array}{ccccccc}\mathrm{H}_{2} & 1300 & 10 & 0.00169 & 0.908 & 0.0227 & 0.00598 \\ & & 25 & 0.00292 & 1.54 & 0.0725 & 0.0103 \\ & 50 & 0.00431 & 2.22 & 0.162 & 0.0153 \\ & & 100 & 0.00621 & 3.13 & 0.340 & 0.0223\end{array}$


Table V. Rate Coefficients for Reactions of Methyltrichlorosilane (continued)

\begin{tabular}{|c|c|c|c|c|c|c|}
\hline Bath Gas & $\mathrm{T}(\mathrm{K})$ & $\mathrm{P}$ (torr) & $\mathrm{k}_{\mathrm{HCl}}\left(\mathrm{s}^{-1}\right)$ & $\mathrm{k}_{\mathrm{CH}_{3}}\left(\mathrm{~s}^{-1}\right)$ & $\mathrm{k}_{\mathrm{H}}\left(\mathrm{s}^{-1}\right)$ & $\mathrm{k}_{\text {tot }} / \mathrm{k}_{\mathrm{uni}}^{\infty}$ \\
\hline & & 760 & 0.0157 & 7.27 & 2.12 & 0.0603 \\
\hline & & 1000 & 0.0174 & 8.01 & 2.62 & 0.0683 \\
\hline
\end{tabular}

In low-pressure limit, $\mathrm{k}_{0}=2.00 \times 10^{8} \mathrm{~cm}^{3} \mathrm{~mol}^{-1} \mathrm{~s}^{-1}$

$\begin{array}{cccccc}1400 \quad 10 & 0.0138 & 7.27 & 0.202 & 0.00294 \\ 25 & 0.0246 & 12.7 & 0.660 & 0.00527 \\ 50 & 0.0374 & 18.9 & 1.51 & 0.00803 \\ 100 & 0.0554 & 27.3 & 3.23 & 0.0120 \\ 760 & 0.152 & 68.5 & 21.9 & 0.0355 \\ 1000 & 0.171 & 76.2 & 27.3 & 0.0408\end{array}$

In low-pressure limit, $\mathrm{k}_{\mathrm{o}}=1.21 \times 10^{9} \mathrm{~cm}^{3} \mathrm{~mol}^{-1} \mathrm{~s}^{-1}$

$\begin{array}{cccccc}1500 & 10 & 0.0796 & 41.4 & 1.24 & 0.00147 \\ 25 & 0.147 & 74.7 & 4.15 & 0.00271 \\ 50 & 0.229 & 114 & 9.67 & 0.00424 \\ 100 & 0.348 & 168 & 21.2 & 0.00652 \\ 760 & 1.03 & 454 & 155 & 0.0209 \\ 1000 & 1.18 & 510 & 195 & 0.0243\end{array}$

In low-pressure limit, $\mathrm{k}_{\mathrm{o}}=5.29 \times 10^{9} \mathrm{~cm}^{3} \mathrm{~mol}^{-1} \mathrm{~s}^{-1}$

2-dimensional rotors. However, the result can be understood by considering all of the entropy gains and losses in going from ground-state MTS to the different transition states. Table VI compares the various contributions to the total $\Delta \mathrm{S}^{\dagger}$ for $\mathrm{H}$ loss versus $\mathrm{CH}_{3}$ loss at $1500 \mathrm{~K}$. Although the $\mathrm{CH}_{3}$ loss transition state has a larger rotational entropy than the transition state for $\mathrm{H}$ loss, this comes at a significant loss of vibrational entropy since the $\mathrm{Si}-\mathrm{C}$ bond has been broken. The low frequency vibrations involving the $\mathrm{Si}-\mathrm{C}$ bond contribute substantially to the entropy of MTS. In contrast, the $\mathrm{H}$ loss transition state has a lower rotational entropy than the $\mathrm{CH}_{3}$ loss transition state but at a fairly minor cost in vibrational entropy since a $\mathrm{C}-\mathrm{H}$ bond has been broken. Vibrations involving the $\mathrm{C}-\mathrm{H}$ bond are much higher in frequency and thus contribute little to the overall entropy. The entropy of the $\mathrm{H}$ loss transition state also increases due to the loss of 

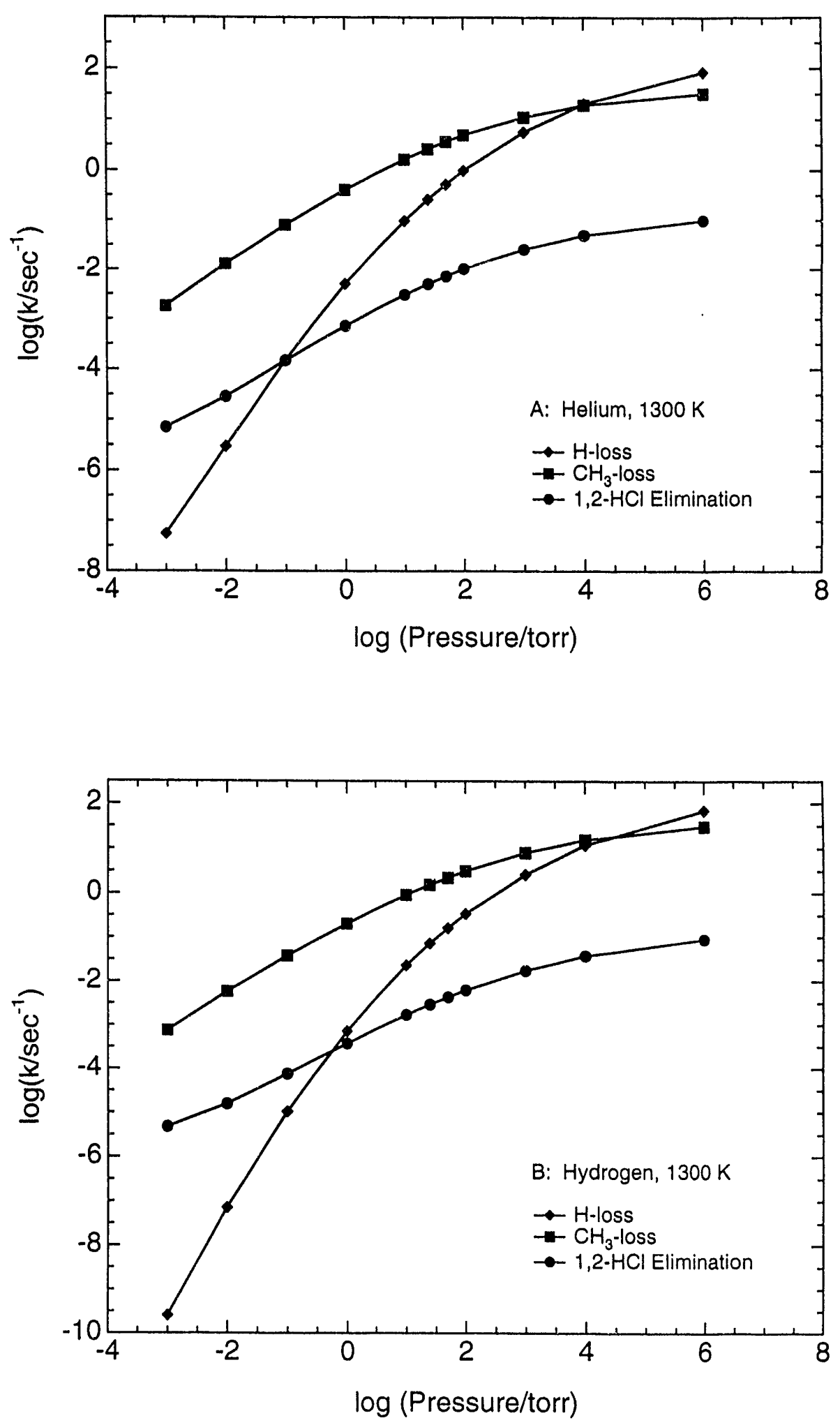

Figure 4: Reaction branching for MTS decomposition as a function of pressure at $1300 \mathrm{~K}$. A): helium bath gas; (B): hydrogen bath gas. 

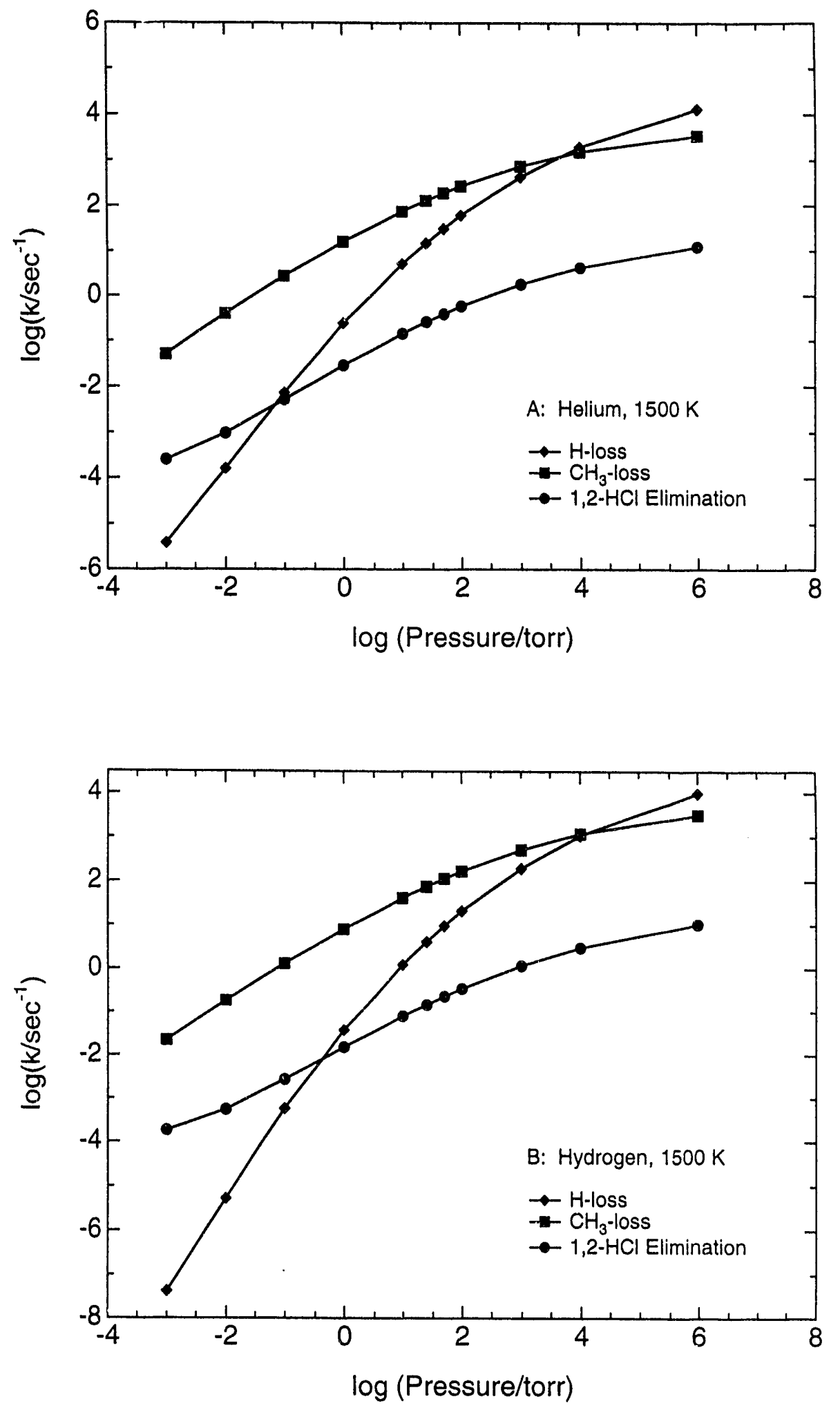

Figure 5: Reaction branching for MTS decomposition as a function of pressure at $1500 \mathrm{~K}$. (A): helium bath gas; (B): hydrogen bath gas. 
molecular symmetry. It should be noted that the $\mathrm{Cl}$ loss transition state (which also has only one 2-dimensional rotor) involves a greater loss of vibrational entropy because vibrations involving the $\mathrm{Si}-\mathrm{Cl}$ bond have a much lower frequency than those involving the $\mathrm{C}-\mathrm{H}$ bond. The result is that the $\mathrm{Cl}$ loss transition state has considerably less entropy than the $\mathrm{H}$ loss transition state and thus has a much lower A-factor (vide supra). To summarize: in the $\mathrm{H}$ loss transition state, loose modes are formed from degrees of freedom that do not contribute much to the entropy of MTS; whereas in the other transition states, the loose modes are formed from degrees of freedom that do contribute significantly to the entropy of MTS. The result is a larger net entropy gain for the $\mathrm{H}$ loss transition state.

Table VI. Entropy changes between MTS and $\mathrm{H}$ loss or $\mathrm{CH}_{3}$ loss transition states ${ }^{\mathbf{a}, \mathbf{b}}$

\begin{tabular}{ccccc}
\hline reaction & $\Delta \mathrm{S}^{\dagger}{ }_{\text {vib }}$ & $\Delta \mathrm{S}^{\dagger}{ }_{\text {rot }}$ & $\Delta \mathrm{S}^{\dagger}{ }_{\text {sym }}$ & $\Delta \mathrm{S}^{\dagger}{ }_{\text {tot }}$ \\
\hline $\mathrm{CH}_{3}$ & -17.0 & $+35.0^{\mathrm{c}}$ & 0 & +18.0 \\
$\mathrm{H}$ & -3.1 & $+26.4 \mathrm{c}$ & +2.2 & +25.5
\end{tabular}

a In cal mol-1 $\mathrm{K}^{-1}$

b At $1500 \mathrm{~K}$

c Includes contributions from the external rotations

E. Sources of Error. As indicated in the introduction, little experimental or theoretical work has been done on these systems so that a quantitative analysis of the error is not straightforward. However, this section will attempt to provide some indication of the uncertainty. Throughout the discussion of these calculations we have indicated where we had to resort to calculated parameters or simplifications of the dynamic model. In most cases we have attempted to asses the potential for error in our calculations resulting from even gross inaccuracy in a parameter. Most of these assessments are included in the foregoing discussion. Extreme modifications in a given parameter typically changed calculated rate coefficients by less than a factor of two.

One important input to the calculations whose accuracy we have not discussed so far is the reaction threshold, which was determined from $a b$ initio calculations due to the paucity of experimental measurements on these systems. Accuracy estimates of the calculations, ${ }^{50}$ which include results from lower level calculations, indicate that the heats of formations of each species are expected to be good to $\pm 2 \mathrm{kcal} / \mathrm{mol}$, particularly for those involved in the bond cleavages. ${ }^{1,11}$ The accuracy of the threshold for $\mathrm{HCl}$ elimination is less easily determined as it involves a calculation using a transition state structure. However, the calculated error estimate for the heat of formation of this transition state is still within $\pm 2 \mathrm{kcal} / \mathrm{mol} .^{1,11}$ To asses the importance of changes in reaction thresholds we calculated rate coefficients with each threshold shifted by $\pm 2 \mathrm{kcal} / \mathrm{mol}$. In the high pressure limit, shifting a threshold down by $2 \mathrm{kcal} / \mathrm{mol}$ causes the rate coefficient to increase by about a factor of 2 for each of the reactions. Correspondingly, shifting a threshold up by $2 \mathrm{kcal} / \mathrm{mol}$ causes the rate coefficient to drop by about a factor of 2 . The same results were observed for calculations at both $1300 \mathrm{~K}$ and $1500 \mathrm{~K} .^{60}$ 
To evaluate the magnitude of this effect in the falloff region we also calculated rate coefficients at 100 torr. A change of $\pm 2 \mathrm{kcal} / \mathrm{mol}$ in a given threshold causes a corresponding increase or decrease in the calculated rate coefficient for that reaction of a factor of 2 to 3 at this pressure. Shifting the threshold for $\mathrm{HCl}$ elimination has essentially no effect on the rate coefficients for the other reactions because it has such a minor contribution to the overall decomposition. Higher thresholds for the $\mathrm{H}$ loss reaction also have little effect on the calculated rate coefficients for the other reactions; a threshold $2 \mathrm{kcal} / \mathrm{mol}$ lower for $\mathrm{H}$ loss decreases the other rate coefficients by about $20 \%$. The minor dependence of the other reactions on $\mathrm{H}$ loss probably occurs because this reaction has a higher threshold to begin with and because it is only the major product at pressures much higher than 100 torr. In other words, at pressures greater than 100 torr, a larger decrease would be observed. Shifting the $\mathrm{CH}_{3}$ loss threshold, however, has a significant effect on the other reactions. With a $2 \mathrm{kcal} / \mathrm{mol}$ lower threshold for $\mathrm{CH}_{3}$ loss, the rates for both of the other reactions drop by about a factor of 2 while a $2 \mathrm{kcal} / \mathrm{mol}$ higher threshold causes a $30 \%$ increase in the coefficient for $\mathrm{HCl}$ elimination and a factor of 2 increase in the $\mathrm{H}$ loss coefficient. Results consistent with these conclusions were observed for calculations at both $1300 \mathrm{~K}$ and $1500 \mathrm{~K}$ using bath gases of helium or hydrogen.

Thus, in the falloff regime, the overall rate is most sensitive to the threshold for Reaction (1), as is expected. ${ }^{27}$ Of the 3 channels, thermodynamic data for the products of Reaction (1) should be the most accurate since $\mathrm{CH}_{3}$ is well characterized and $\mathrm{SiCl}_{3}$ has fewer empirical corrections ${ }^{11}$ required to obtain its heat of formation than $\mathrm{CH}_{2} \mathrm{SiCl}_{3}$. Of course its relative threshold will still depend on the thermodynamic data for the other reactions.

\section{Discussion}

A. Significance for organosilicon chemistry. As discussed in the introduction, experimental and theoretical treatments of the chlorinated organosilanes are nearly non-existent. The results of this study thus provide new insight into the characteristic features of chlorinated organosilicon chemistry, in particular the ways in which reactions of these molecules differ from those of species containing no chlorine and from analogous hydrocarbon chemistry.

Our results highlight two factors that have an important influence on the reactions of chlorinated organosilanes. The first is the high strength of the $\mathrm{Si}-\mathrm{Cl}$ bond, which in MTS ${ }^{11}$ is 114 kcal mol-1 vs. $92 \mathrm{kcal} \mathrm{mol}^{-1}$ for the $\mathrm{Si}-\mathrm{H}$ bond in $\mathrm{CH}_{3} \mathrm{SiH}_{3} .{ }^{1}$ The effect of this large bond dissociation energy is to make pathways that do not involve breaking the bond, such as $\mathrm{CH}_{3}$-loss and $\mathrm{H}$-loss, energetically favorable. In addition, the presence of these strong bonds undoubtedly reduces the efficiency of silylene elimination reactions (for example, Reactions 5 and 6), although the magnitude of this effect is difficult to evaluate relative to the reduction in rate caused by the increased electronegativity of chlorine. ${ }^{61}$ As discussed earlier, silylene eliminations in MTS (Reactions 5 and 6; see Figure 1) are relatively high-energy pathways for decomposition. In addition, the 1,2-elimination pathway in MTS $\left(96.9 \mathrm{kcal} \mathrm{mol}^{-1}\right.$ at $1400 \mathrm{~K}$ in the high-pressure limit) is energetically accessible; its activation barrier is actually lower than the barriers for $\mathrm{H}$ loss and $\mathrm{CH}_{3}$ loss (103.8 kcal mol-1 and $97.5 \mathrm{kcal} \mathrm{mol}^{-1}$ at $1400 \mathrm{~K}$ in the high-pressure limit.) This contrasts with the situation in $\mathrm{CH}_{3} \mathrm{SiH}_{3}$, where the corresponding reaction, 1,2-elimination of $\mathrm{H}_{2}$, is much higher than other reaction pathways. ${ }^{7}$ 
The second important factor is the formation of product fragments with large moments of inertia, which leads to large A-factors (and hence, higher reaction rates) for processes that would normally be thought to be relatively slow. In the case of MTS, this is illustrated by the H-loss reaction (Reaction 4), with a high-pressure A-factor at $1400 \mathrm{~K}$ that is predicted to be greater than $10^{19} \mathrm{sec}^{-1}$. This can be compared with the analogous reaction for $\mathrm{CH}_{4}$, where the high-pressure A-factor ${ }^{62}$ is $1.0 \times 10^{15} \mathrm{sec}^{-1}$. (Note that no data are available to make the direct comparison with the analogous $\mathrm{H}$-loss channel in $\mathrm{CH}_{3} \mathrm{SiH}_{3}$, due to the availability of lower energy pathways such as $\mathrm{H}_{2}$ or $\mathrm{CH}_{4}$ elimination.) Presumably, high A-factors will also be observed in other chlorinated organosilanes. Steric factors may, however, reverse (or at least mitigate) this trend; the bulkiness of groups such as $\mathrm{SiCl}_{3}$ relative to $\mathrm{SiH}_{3}$ may tighten the transition state, thus lowering the transition state entropy.

The two factors discussed above combine to make bond-scission pathways the most efficient ones for MTS unimolecular decomposition. This indicates that intuition based on the reactivity of organosilanes that do not contain $\mathrm{Si}-\mathrm{Cl}$ bonds cannot be straightforwardly extended to chlorinated species, since silylene elimination reactions are usually the lowest energy channels for simple organosilanes, especially for compounds containing at least one $\mathrm{Si}-\mathrm{H}$ bond. Interestingly, the result is that MTS reacts more like methane than silane (at least in the high-pressure limit), since $\mathrm{H}$-atom loss, which is the lowest energy unimolecular decomposition pathway for methane, is more accessible in MTS due to the high activation barriers for other pathways. In fact, the $\mathrm{C}-\mathrm{H}$ bond dissociation energies in MTS and $\mathrm{CH}_{4}$ are nearly the same $\left(102.2 \mathrm{kcal} \mathrm{mol}^{-1}\right.$ in MTS vs. 104.8 in $\mathrm{CH}_{4}$ at $298 \mathrm{~K}$ ) and their high-pressure activation barriers are also similar (103.8 kcal $\mathrm{mol}^{-1}$ for MTS vs. $100.4 \mathrm{kcal} \mathrm{mol}^{-1}$ for $\mathrm{CH}_{4}{ }^{62}$ ). These characteristics of chlorinated organosilanes, combined with the dominance of other bond scission decomposition paths, lead to the possibility that radical chain processes may occur during the pyrolysis of chlorinated organosilanes, which can complicate experimental measurements of decomposition rates. Mechanisms of this type have been observed for the decomposition of several methylchlorosilanes, ${ }^{10}$ although MTS was not among them.

B. Implications for SiC CVD. The results of this study have several important implications for understanding SiC CVD processes that use MTS as a reactant. First, the experimental reaction rates of $\mathrm{BL},{ }^{21}$ which have been widely used in modeling $\mathrm{SiC} C \mathrm{CVD}$, are substantially higher than those predicted by the RRKM calculations. Figure 6 shows a comparison. of the total MTS decomposition rate as determined by BL at a pressure of 760 torr in hydrogen, compared with the RRKM results for the same conditions. The MTS decomposition rate predicted by $\mathrm{RRKM}\left(k_{\text {tot }}\left(\mathrm{H}_{2}, 760\right.\right.$ torr $\left.)=2.08 \times 10^{16} \mathrm{exp}(-90261 / \mathrm{RT})\left(\mathrm{sec}^{-1}\right), \mathrm{T}=950-1100 \mathrm{~K}\right)$ is a factor of 5-6 smaller than the experimental result $\left(k_{t o t}\left(\mathrm{H}_{2}, 1 \mathrm{~atm}\right)=7.6 \times 10^{14} \mathrm{exp}(-80300 / \mathrm{RT})\left(\mathrm{sec}^{-1}\right), \mathrm{T}=\right.$ $975-1025 \mathrm{~K})$. Our evaluation of the uncertainties associated with the RRKM calculations indicates that the rate reported in the BL paper is outside the estimated error of the calculations. In particular, transition state theory is inherently expected to overestimate reaction rates because it does not account for barrier recrossing. ${ }^{30}$ Barring a gross inaccuracy in a reaction threshold (unlikely, vide supra), our calculations would be expected to overestimate the decomposition rate. The reasons for this discrepancy are unclear; radical chain processes are a possibility, especially since BL's measurements were made at relatively low temperatures. Unfortunately, the BL paper only reports an Arrhenius expression and no data or error analysis making a critical 


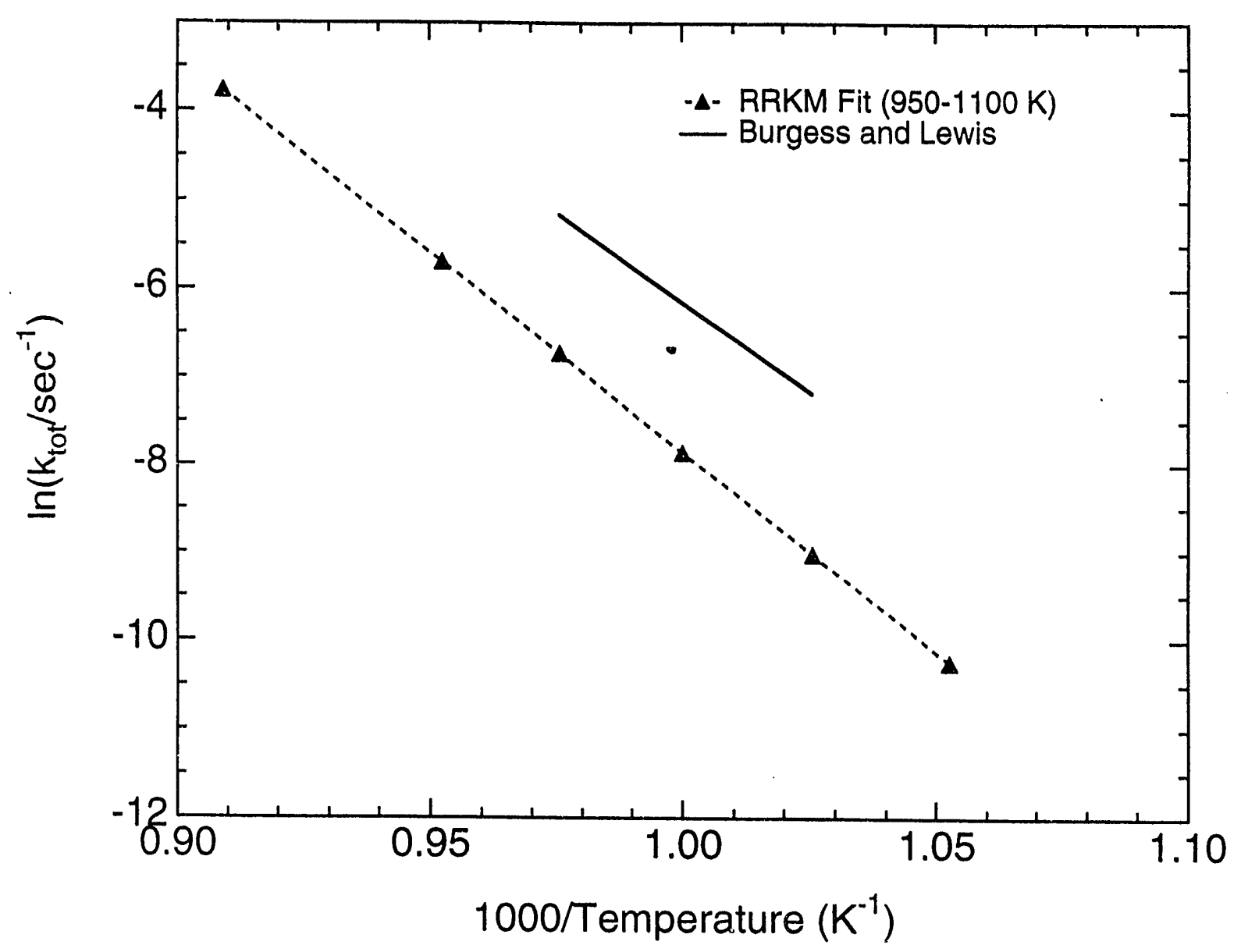

Figure 6: Comparison of experimental results of Burgess and Lewis (Ref. 21) with RRKM predictions of the total MTS decomposition rate at 760 torr in hydrogen. Triangles indicate temperatures at which the RRKM calculations were performed; the dashed line is a linear least-squares fit of the Arrhenius rate expression to these points.

comparison difficult. Ironically, extrapolation of the BL results to typical SiC CVD temperatures $(1300-1500 \mathrm{~K})$ brings them into closer agreement with the RRKM results, a fit to their data yields $k_{\text {tot }}\left(\mathrm{H}_{2}, 760\right.$ torr $)=3.72 \times 10^{14} \exp (-80847 / \mathrm{RT})\left(\mathrm{sec}^{-1}\right)$. Further experimental measurements are required to resolve this discrepancy. Based on our evaluation of the uncertainties in the RRKM rate constants, we conclude that these rates are more likely to represent the true unimolecular MTS decomposition rate than the BL experimental result, which was obtained from a complex system in which a large number of reactions may have been occurring.

A second point relevant to SiC CVD is that pressure effects on the decomposition rate of MTS are large. For example, at atmospheric pressure and $1400 \mathrm{~K}, k / k_{\infty}$ is 0.036 , while at 25 torr, $k / k_{\infty}$ is 0.0053 . Thus, accurate simulations of SiC CVD processes must take into account the pressure falloff of the reactant pyrolysis reactions. In particular, it should be noted that the results of BL should not be extended to low pressures. 
From a mechanistic standpoint, the RRKM results show that at atmospheric pressure the predominant decomposition modes are expected to be loss of $\mathrm{H}$ and $\mathrm{CH}_{3}$. In the presence of hydrogen carrier gas, $\mathrm{CH}_{3}$ will lead to the production of large quantities of methane. The $\mathrm{SiCl}_{3}$ radical that is formed can undergo unimolecular decomposition to form $\mathrm{SiCl}_{2}$ and $\mathrm{Cl}\left(\Delta H_{r x n}^{\circ}\right.$ $\left.(298 \mathrm{~K})=68.8 \mathrm{kcal} \mathrm{mol}^{-1}\right)$ or react exothermically with $\mathrm{CH}_{3}$ to form $\mathrm{CH}_{3} \mathrm{Cl}$ and $\mathrm{SiCl}_{2}\left(\Delta H_{r x n}^{\circ}\right.$ $\left.(298 \mathrm{~K})=-15.0 \mathrm{kcal} \mathrm{mol}^{-1}\right)$ or react with $\mathrm{H}_{2}$ to form $\mathrm{SiCl}_{3} \mathrm{H}$ and $\mathrm{H}\left(\Delta H^{\circ}{ }_{r x n}(298 \mathrm{~K})=10.9 \mathrm{kcal}\right.$ $\left.\mathrm{mol}^{-1}\right)$. Thus, the gas-phase species in highest concentration during deposition may be $\mathrm{SiCl}_{2}$, $\mathrm{CH}_{4}$, and $\mathrm{SiCl}_{3} \mathrm{H}$. The reactivity of $\mathrm{SiCl}_{2}$ at high temperatures is uncharacterized, pointing again to the need for additional experimentation.

Organosilicon species may play a role in the deposition of $\mathrm{SiC}$, especially if they are radicals. The surface reactivity of organosilicon radicals should be much greater than that of methane, which is likely to be the most abundant hydrocarbon present in the gas-phase and whose reactive sticking coefficient is probably ${ }^{63} 10^{-5}-10^{-4}$. Our results show that two organosilicon radicals ${ }^{64}$ are formed by the initial decomposition of $\mathrm{MTS}, \mathrm{Cl}_{2} \mathrm{Si}=\mathrm{CH}_{2}$ and $\mathrm{CH}_{2} \mathrm{SiCl}_{3}$. The latter species, assuming that its reactivity is similar to methane, will be rapidly reconverted to MTS via reaction with the hydrogen carrier gas. Use of inert carrier gas or high MTS partial pressures favor relatively high concentrations of this molecule, however. The remaining radical, the silaethylene $\mathrm{Cl}_{2} \mathrm{Si}=\mathrm{CH}_{2}$, represents $<0.2 \%$ of the products at all pressures examined. The surface reactivity of this molecule is unknown; if it is similar to $\mathrm{C}_{2} \mathrm{H}_{4}\left(\Gamma \sim 0.001\right.$ on silicon surfaces $\left.{ }^{\mathrm{l}} 3\right)$, it could contribute significantly to the deposition of carbon. Thus, the calculations reported here indicate that pathways are available for the production of organosilicon radicals with potentially high surface reactivity. Their concentrations relative to $\mathrm{CH}_{4}$ must first be known, however, to determine their importance to the deposition process.

Finally, the effect of substituting an inert carrier gas such as helium for hydrogen in a SiC CVD process can be evaluated from the RRKM results. The data shown in Figure 2 indicate that the rates of Reactions (1) and (4) increase by less than a factor of two when the carrier gas is helium instead of hydrogen. The rate of Rexction (2) increases more, about a factor of 3.5 at 25 torr. Such effects are relatively small, however, compared with the change induced by the substitution of a reactive gas such as hydrogen for an unreactive one such as helium. Thus, a different gas-phase product distribution is expected from the two carrier gases, which could alter the deposition $\mathrm{SiC}$ deposition rate substantially.

\section{Conclusions}

Using RRKM theory, we calculated rate constants for the decomposition of MTS in both the high-pressure limit and in the falloff regime. The results show that $\mathrm{Si}-\mathrm{C}$ bond cleavage, $\mathrm{C}-\mathrm{H}$ bond cleavage, and $\mathrm{HCl}$ elimination (Reactions (1), (2), and (4)) are the predominant thermal decomposition pathways. In the high-pressure limit, Reaction (2) is the most efficient decomposition paihway at the temperatures of interest. However, at atmospheric pressure, both Reaction (1) and Reaction (2) contribute. As the pressure decreases, the rate of Reaction (2) decreases substantially. At the lowest pressures typically accessible to SiC CVD ( 0.1 - 1 torr $)$ Reaction (1) dominates the decomposition. $\mathrm{HCl}$ elimination, Reaction (4), is never a major 
product over the pressure range used in these calculations. Qualitatively, the branching behavior can be understood on the basis of the A-factor and activation energy for each reaction pathway.

The relative importance of the $\mathrm{H}$-atom loss channel (Reaction (2)) is surprising. The large A-factor for this reaction is due to the relatively minor loss of vibrational entropy from breaking the $\mathrm{C}$-H bond. This more than makes up for the lower entropy contribution of only one 2-dimensional rotor in the $\mathrm{C}-\mathrm{H}$ bond cleavage transition state. We also point out that, in contrast to other organosilanes, this reaction is thermodynamically accessible because the strong $\mathrm{Si}-\mathrm{Cl}$ bonds in MTS raise the activation barriers for reactions that are normally considerably lower than that for H-loss.

Prior to this work, little information was available on the gas-phase kinetic behavior of chlorinated organosilanes even though they are an important class of compounds of interest in many fields. The results reported here provide new insight into the decomposition reactions of these compounds, which are strongly influenced by the large dissociation energy of the $\mathrm{Si}-\mathrm{Cl}$ bond. The behavior of these systems is predicted to be very different from the non-chlorinated organosilicon analogs. Along with mechanistic discussions ${ }^{10}$ the present study provides a critically needed starting point for future theoretical and experimental investigations of the reactivity of these systems.

\section{References}

(1) Allendorf, M. D.; Melius, C. F. J. Phys. Chem. 1992, 96, 428.

(2) Walsh, R. In The Chemistry of Organic Silicon Compounds; S. Patai and Z. Rappoport, Ed.; John Wiley and Sons: New York, 1989; pp 371-391.

(3) Safarik, I.; Sandhu, V.; Lown, E. M.; Strausz, O. P.; Bell, T. N. Res. Chem. Intermed. 1990, 14, 105-131.

(4) Gaspar, P. P. In Reactive Intermediates; M. Jones Jr. and R. A. Moss, Ed.; Wiley: New York, 1985; Vol. 3; pp 333-427.

(5) Tang, Y.-N. In Reactive Intermediates; R. A. Abramovitch, Ed.; Plenum: New York, 1982; Vol. 2; pp 297-367.

(6) Gordon, M. S.; Gano, D. R. J. Am. Chem. Soc. 1984, 106, 5421.

(7) Gordon, M. S.; Truong, T. N. Chem. Phys. Lett. 1987, 142, 110.

(8) Neudorfl, P. S.; Lown, E. M.; Safarik, I.; Jodhan, A.; Strausz, O. P. J. Am. Chem. Soc. 1987, 109, 5780 .

(9) Sawrey, B. A.; O'Neal, H. E.; Ring, M. A.; Coffey Jr., D. Int. J. Chem. Kinetics 1984, 16,31 . 
(10) Davidson, I. M. T.; Dean, C. E. Organometallics 1987, 6, 966.

(11) Allendorf, M. D.; Melius, C. F. J. Phys. Chem. 1993, 97, 720.

(12) Benson, S. W. Thermochemical Kinetics; 2nd ed.; J. Wiley and Sons: New York, 1976.

(13) McMillen, D. F.; Golden, D. M. Ann. Rev. Phys. Chem. 1982, 33, 493.

(14) Voorhoeve, R. J. H. Organohalosilanes: Precursors to Silicones; Elsevier: New York, 1967.

(15) Besmann, T. M.; Sheldon, B. W.; Kaster, M. D. Surface and Coatings Technol. 1990, $43 / 44,16 ?$.

(16) Motojima, S.; Hásegawa, M. J. Vac. Sci. Technol. A 1990, 8, 3763.

(17) Cheng, D. J.; Shyy, W. J.; Kuo, D. H.; Hon, M. H. J. Electrochem. Soc. 1987, 134, $3 ! 45$.

(18) Kuo, D. H.; Cheng, D. J.; Shyy, W. J.; Hon, M. H. J. Electrochem. Soc. 1990, 137, 3688 .

(19) So, M. G.; Chun, J. S. J. Vac. Sci. Technol. A 1988, 6, 5.

(20) Yeheskel, J.; Agam, S.; Dariel, M. S. Chemical Vapor Deposition 1990; K. E. Spear and G. W. Cullen, Fds. The Electrochemical Society Softbound Proceedings Series,Seattle, 1990.

(21) Tsurgess, J. N.; Lewis, T. J. Chemistry and Industry 1974, 76.

(22) Whitman, L. J.; Jo;ce, S. A.; Yarmoff, J. A.; Mcfeely, F. R.; Terminello, I.. J. Surf. Sci. 1990, 232, 297.

(23) NoorBatcha, I; Raff, L M.; Thompson, D. L. J. Chem. Phys. 1984, 81, 3715.

(24) Hc, P.; Breiland, W. G.: Buss, R. J. J. Chem. Phys. 1989, 91, 2627.

(25) Robertson, R. M.; Rossi, M. J. Appl. Phys. Lett. 1989, 54, 185.

(26) Perrin, J.; Broekhuizen, T. Appl. Phys. Lett. 1987, 50, 433.

(27) Allendorf, M. D.; Melius, C. F.; Osterheld, T. H. accepted for publication in Chemical Vapor Deposition 1993 Softbound Proceedings Series; G. W. Cullen and K. Jenson, Eds. The Electrochemical Society, Pennington, NJ, 1993. 
(28) This simplified version of the statistical adiabatic channel model uses the maximum free energy criterion to determine the location of the transition state. The model uses a single adjustable parameter to determine the reaction coordinate potential energy curve, the value of which is determined empirically, using data from known reactions. Reaction rates can then be determined from spectroscopic and thermodynamic data for the reactants and products only. It should be noted that the full statistical adiabatic channel model is not considered less sophisticated than RRKM theory.

(29) Quack, M.; Troe, J. Ber. Bunsen Gesell. Phys. Chem. 1977, 81, 329.

(30) Gilbert, R. G.; Smith, S. C. Theory of Unimolecular and Recombination Reactions; Blackwell Scientific Publications: Oxford, 1990.

(31) Gardiner Jr., W. C.; Troe, J. In Combustion Chemistry; W. C. Gardiner Jr., Ed.; SpringerVerlag: New York, 1984; pp 173-196.

(32) Jordan, M. J. T.; Smith, S. C.; Gilbert, R. G. J. Phys. Chem. 1991, 95, 8685.

(33) Pitt, I. G.; Gilbert, R. G.; Ryan, K. R. Aust. J. Chem. 1990, 43, 169.

(34) Greenhill, P. G.; Gilbert, R. G. J. Phys. Chem. 1986, 90, 3104.

(35) Berne, B. J.; Borkovec, M.; Straub, J. E. J. Phys. Chem. 1988, 92, 3711.

(36) Forst, W. Theory of Unimolecular Reactions; Academic Press: New York, NY, 1973.

(37) Karas, A. J.; Gilbert, R. G. J. Phys. Chem. 1992, 96, 10893.

(38) Klippenstein, S. J.; Marcus, R. A. J. Chem. Phys. 1989, 91, 2280.

(39) Klippenstein, S. J. J. Chem. Phys. 1990, 93, 2418.

(40) Klippenstein, S. J. J. Chem. Phys. 1991, 94, 6469.

(41) Marcus, R. A. Science 1992, 256, 1523.

(42) Miller, W. H. J. Chem. Phys. 1976, 65, 2216.

(43) Ravi, R.; Takoudis, C. G. J. Electrochem. Soc. 1992, 139, 1994.

(44) Robinson, P. J.; Holbrook, K. A. Unimolecular Reactions; John Wiley and Sons Ltd.: New York, NY, 1972.

(45) Smith, S. C.; Gilbert, R. G. Int. J. Chem. Kinet. 1988, 20, 307.

(46) Troe, J. J. Chem. Phys. 1977, 66, 4745. 
(47) Troe, J. J. Chem. Phys. 1977, 66, 4758.

(48) Wardlaw, D. M.; Marcus, R. A. Adv. Chem. Phys. 1987, 70, 231.

(49) Gilbert, R. G.; Jordan, M. J. T.; Smith, S. C. UNIMOL program suite, 1992

(50) Ho, P.; Melius, C. F. J. Phys. Chem. 1990, 94, 5120.

(51) Soliman, M. S.; Khattab, M. A.; El-Kourashy, A. G. Spectrochim. Acta 1983, 39A, 621.

(52) Chase, M. W. J.; Davies, C. A.; Downey, J. R. J.; Frurip, D. J.; McDonald, R. A.; Syverud, A. N. J. Phys. Chem. Ref. Data 1985, 14, 860.

(53) Hehre, W. J.; Radom, L.; Schleyer, P. v. R.; Pople, J. A. Ab Initio Molecular Orbital Theory; Wiley: New York, NY, 1986.

(54) Gilbert, R. G. J. Chem. Phys. 1984, 80, 5501.

(55) Lim, K. F.; Gilbert, R. G. J. Chem. Phys. 1986, 84, 6129.

(56) Lim, K. F.; Gilbert, R. G. J. Chem. Phys. 1990, 92, 1819.

(57) Melius, C. F., personal communication.

(58) Both the BRW model and trajectory calculations can overestimate energy transfer values for collisions with He. For a discussion see References 30 and 54-56.

(59) Quack, M.; Troe, J. In A Specialist Periodical Report. Gas Kinetics and Energy Transfer; P. G. Ashmore and R. J. Donovan, Ed.; The Chemical Society: London, 1977; Vol. 2.

(60) The ratio describing the change in the calculated rate resulting from a different reaction threshold is simply exp[( $\left.\left.E_{1}-E_{2}\right) / R T\right]$. This ratio is essentially 2 in all cases since $E_{1}$ is nominally $100 \mathrm{kcal} / \mathrm{mol}$ for all of the reactions considered and the temperature increase from $1300 \mathrm{~K}$ to $1500 \mathrm{~K}$ is relatively minor.

(61) Sosa, C.; Schlegel, H. B. J. Am. Chem. Soc. 1984, 106, 5847.

(62) Warnatz, J. In Combustion Chemistry; W. C. Gardiner Jr., Ed.; Springer-Verlag: New York, 1984.

(63) Stinespring, C. D.; Wormhoudt, J. C. J. Appl. Phys. 1989, 65, 1733.

(64) In this paper we use the term "radical" to refer to any unsaturated species. 


\section{INITIAL DISTRIBUTION \\ UNLIMITED RELEASE}

Dr. Peter Angelini

Bldg. 4515

Oak Ridge Natonal Laboratories

P.O. Box 2008, 1 Bethel Valley Road

Oak Ridge, TN 37831-6065

Dr. Charles A. Sorrell

Adv. Industrial Concepts Div., CE-232

U.S. DOE - CE

Forrestal Building, 1000 Independence Ave.

Washington, DC 20585

Dr. K.B. Alexander

Metals and Ceramics Division

Oak Ridge National Laboratory

P.O. Box 2008

Oak Ridge, TN 37831-6068

Dr. Theodore M. Besmann

Oak Ridge National Laboratories

P.O. Box 2008

Oak Ridge, TN 37831-6063

Dr. R.P. Currier

C348

Los Alamos National Laboratory

P.O. Box 1663

Los Alamos, NM 87545

Dr. D.J. Devlin

K762

Los Alamos National Laboratory

P.O. Box 1663

Los Alamos, NM 87545

Dr. Greg Glaitzmaier

NREL

1617 Cole Blvd.

Golden, CO 80401

Dr. Suleyman A. Gokoglu

NASA Lewis Research Center

Mail Stop 106-1

Cleveland, $\mathrm{OH} 44135$

Dr. John H. Kinney

Mail Stop L-356

Lawrence Livermore National Laboratory

Livermore, CA 94550
Dr. Gerd M. Rosenblatt

Building 50A, Room 4119

Lawrence Berkeley Laboratory

1 Cyclotron Road

Berkeley, CA 94720

Dr. Michael Zachariah

National Institute of Standards and Technologies

Building 221, Rm. B312

Gaithersburgh, MD 20899

Prof. Peter B. Armentrout

Department of Chemistry

University of Utah

Henry Eyring Building

Salt Lake City, Utah 84112

Prof. Dieter Baeuerle

Johannes-Kepller-Universitat Linz

Institut fur Angewandte Physik

A-4040 Linz

Austria

Prof. C. Bernard

Laboratorie de Thermodynamique

ENSEEG

Bp. 75, 28402

St. Martin d'Héres

France

Dr. Ken Brezinsky

Department of Mechanical \& Aerospace Engineering

Princeton University

Engineering Quadrangle, D329

Princeton, NJ 08544

Prof. Jan-Otto Carlsson

Uppsala University

Chemistry Department

Box 531

S-75121 Uppsala

Sweden

Prof. David S. Dandy

Dept. of Agricultural and Chemical Engineering

Colorado State University

Fort Collins, CO 80523

Prof. James Edgar

Department of Chemical Engineering

Kansas State University

Manhattan, Kansas 66506-5102 
Prof. James W. Evans

Dept. of Materials Science and Mineral

Engineering

University of California

Berkeley, CA 94720

Prof. Richard C. Flagan

Environmental Engineering

California Institute of Technology

138-78

Pasadena, CA 91125

Prof. Michael Frenklach

Dept. of Materials Science and

Engineering

202 Academic Projects Building

Pennsylvania State University

University Park, PA 16802

Prof. Bernard Gallois

Dept. of Materials Science

Stevens Institute of Technology

Castle Point on the Hudson

Hoboken, NJ 07030

Prof. Steven M. George

Department of Chemistry

University of Colorado

Boulder, CO 80309

Prof. Irvin Glassman

Dept. of Mechanical \& Aerospace

Engineering

Princeton University

Princeton, NJ 08544

Prof. Mark S. Gordon

Department of Chemistry

North Dakota State University

Fargo, ND 58105

Prof. David Gutman

Department of Chemistry

Catholic University of America

Washington, DC 20064

Prof. John Haggerty

Department of Materials Sciences

Massachusetts Institute of Technology

12-009

Cambridge, MA 02139
Professor D. Lynn Johnson, Chairman

Dept. of Materials Science \& Engineering

Northwestern University

The Technology Institute

Evanston, IL 60201

Dr. Sean King

Dept. of Materials Science and Engineering

North Carolina State University

Route 229

Rayleigh, NC 27695

Prof. M.C. Lin

Department of Chemistry

Emory University

Atlanta, GA 30322

Prof. Paul Marshall

Department of Chemistry

University of North Texas

P.O. Box 5068

Denton, TX 76203-5068

Dr. Roger Naslain

Laboratoire des Compsites

Thermostructuraux

Domaine Universitaire

33600 Pessac

France

Prof. H. Edward O'Neal

Department of Chemistry

San Diego State University

San Diego, CA 92182-0328

Prof. Emil Pfender

Institute of Technology

244 Mechanical Engineering Building

111 Church Street S.E. Univ. of Minnesota

Minneapolis, MN 55455

Prof. S.E. Pratsinis

Chemical \& Nuclear Engineering

University of Cincinnati

627 Rhodes Hall, Mail Loc. 171

Cincinnati, $\mathrm{OH}$ 45221-0171

Prof. Robert J. Santoro

Department of Mechanical Engineering

Pennsylvania State Universtiy

313A Mechanical Engineering Building

University Park, PA 16802 
Dr. Daniel J. Skamser

Dept. of Materials Science and Engineering

Northwestern University

MLSF 20362225 N. Campus Drive

Evanston, IL 60208-3108

Prof. Karl E. Spear

Dept. of Ceramic Science and Engineering

Pennsylvania State University

201 Steidle Building

University Park, PA 16802

Prof. Thomas L. Starr

Room 113

Baker Building

Georgia Institute of Technology

Atlanta, GA 30332-0245

Prof. Robin Walsh

Department of Chemistry

University of Reading

Whiteknights

Reading RG62AD

England

Dr. Thomas H. Baum

IBM Almaden Research Center 650 Harry Rd.

San Jose, CA 95120

Dr. H.F. Calcote

Director of Research

Aerochem Research Laboratories

P.O. Box 1

Princeton, NJ 08542

Dr. Stephan de la Veaux

Experimental Station, E304/C216

E.I. DuPont

Wilmington, DE 19880-0304

Dr. William Felder

Aerochem Research Laboratories

P.O. Box 1

Princeton, NJ 08542

Dr. Stephen O. Hay

United Technologies Research Center

MS-90 Propulsion Science

Silverlane

East Hartford, CT 06108
Dr. John A. Mucha

Room 1D-357

AT\&T Bell Laboratories

600 Mountain Avenue

Murray Hill, NJ 07974-2070

Dr. Bruce R. Palmer

Manager, Exploratory Research

Kerr-McGee Corporation

P.O. Box 25861

Oklahoma City, OK 73125

Dr. Michel Pons

Laboratoire de Science des Surfaces et

Matériaux Carbonés

Institut National Polytechnique de Grenoble

ENSEEG

38402 Saint-Martin-D'Heres Cedex

France

Mr. Peter Reagan

Project Manager, CVD Composites

Thermo Trex Corporation

74 West Street, P.O. Box 9046

Waltham, MA 02254-9046

Dr. Andrew J. Sherman

Ultramet

12173 Montague Street

Pacoima, CA 91331

Dr. Richard Silberglitt

Technology Assessment and Transfer, Inc.

133 Defense Highway, \#212

Annapolis, MD 21401

Dr. Richard G. Tave

Day and Zimmermann, Inc.

1818 Market Street

Philadelphia, PA 19103

Dr. Jody Wormhoudt

Aerodyne Research Inc.

45 Manning Road

Bilerica, MA 01821

1112 S.T. Picraux

1126 W.G. Breiland

1126 M.E. Coltrin

1126 P. Ho 
1700 R.J. Eagan

Attn: 1703 D.W. Schaefer

1708 R.E. Loehman

6200 D.E. Arvizu

6211 G.A. Carlson

8000 J.C. Crawford

Attn: 8100 E.E. Ives

8200 R.J. Detry

8300 W.J. McLean

Attn: 8302 W. Bauer

8341 W.G. Wolfer

8342 R.H. Stulen

8351 L.A. Rahn

8355 G.A. Fisk

8347 A. Pontau

8362 R.W. Carling

8366 C.M. Hartwig

8347 D.A. Outka

8353 C.F. Melius (3)

8353 F.P. Tully

Attn: R.J. Behrens

D.W. Chandler

J.L. Durant Jr.

J.A. Miller

8361 M.D. Allendorf (10)

8745 R.J. Kee

Attn: W.G. Houf

R.S. Larson

E. Meeks

8535 Publications for OSTI (10)

8535 Publications/Technical Library Processes, 7141

7141 Technical Library Processes Department (3)

8523-2 Central Technical Files (3) 


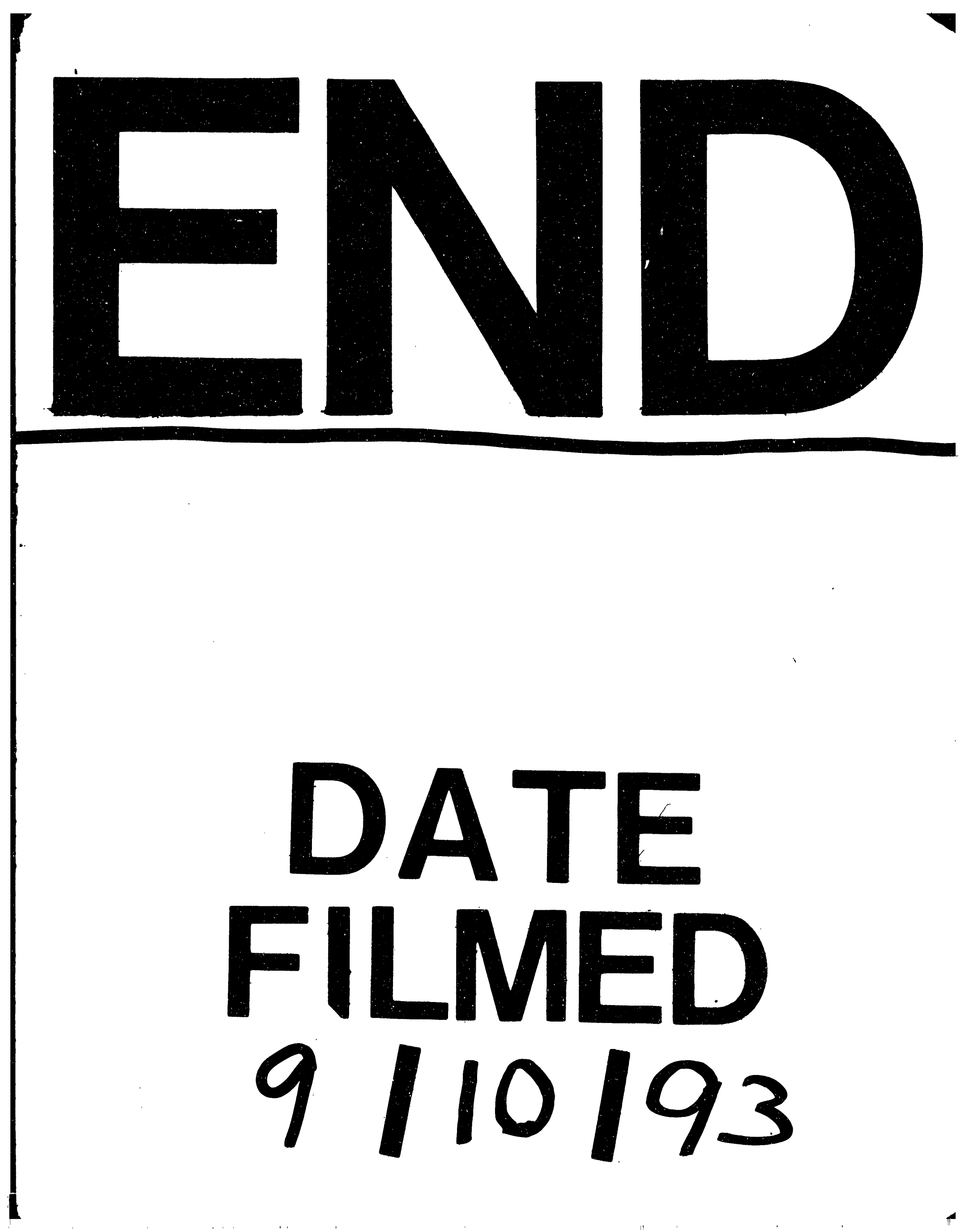


